\title{
The Mosaic of Midget Ganglion Cells in the Human Retina
}

\author{
Dennis M. Dacey \\ Department of Biological Structure, The University of Washington, Seattle, Washington 98195
}

To study their detailed morphology, ganglion cells of the human retina were stained by intracellular tracer injection, in an in vitro, whole-mount preparation. This report focuses on the dendritic morphology and mosaic organization of the major, presumed color-opponent, ganglion cell class, the midget cells. Midget cells in the central retina were recognized by their extremely small dendritic trees, $\sim 5-10 \mu \mathrm{m}$ in diameter. Between 2 and $6 \mathrm{~mm}$ eccentricity, midget cells showed a steep, 10-fold increase in dendritic field size, followed by a more shallow, three- to fourfold increase in the retinal periphery, attaining a maximum diameter of $\sim 225 \mu \mathrm{m}$. Despite large local variation in dendritic field size, midget cells formed one morphologically distinctive class at all retinal eccentricities.

Two midget cell types were distinguished by their dendritic stratification in either the inner or outer portion of the inner plexiform layer (IPL), and presumably correspond to $\mathrm{ON}$ - and OFF-center cells respectively. The mosaic organization of the midget cells was examined by intracellularly filling neighboring cells in small patches of retina. For both the inner and outer midget populations, adjacent dendritic trees apposed one another but did not overlap, establishing a coverage of no greater than 1 . The two mosaics differed in spatial scale, however: the outer midget cells showed smaller dendritic fields and higher cell density than the inner midget cells. An outer:inner cell density ratio of 1.7:1 was found in the retinal periphery. An estimate of total midget cell density suggested that the proportion of midget cells increases from about $45 \%$ of total ganglion cell density in the retinal periphery to about $\mathbf{9 5} \%$ in the central retina. Nyquist frequencies calculated from midget cell spacing closely match a recent measure of human achromatic spatial acuity (Anderson et al., 1991), from $\sim 6^{\circ}$ to $55^{\circ}$ eccentricity.

Outside the central retina, midget cell dendrites arborized in clusters within the overall dendritic field. With increasing eccentricity, the dendritic clusters increased in number and remained small ( $\sim$ 10-20 $\mu \mathrm{m}$ diameter) relative to the size of the dendritic field. Because neighboring midget cell dendritic trees do not overlap, the mosaic as a whole showed

\footnotetext{
Received Nov. 24, 1992; revised June 16, 1993; accepted June 24, 1993.

I am especially grateful to Kim Allen and the staff of the Lions Eye Bank for the timely retrieval of donor eyes for this research and for the contributions of Michael Petersen. Christine Curcio, Kate Mulligan, Helen Sherk, Peter Sterling, and Heinz Wässle offered helpful comments on various drafts of the manuscript. Dan Possin helped with histological sections and the photographers of the Department of Ophthalmology, University of Washington provided excellent service. This work was supported by U.S. Public Health Service Grants EY 06678 and EYO1730 (Vision Research Core).

Correspondence should be addressed to Dennis Dacey, Ph.D., The University of Washington, Department of Biological Structure, SM-20, Seattle, WA 98195. Copyright (C) 1993 Society for Neuroscience $0270-6474 / 93 / 135334-22 \$ 05.00 / 0$
}

a pattern of clusters and holes. We hypothesize that midget cell dendritic trees may contact individual axon terminals of some midget bipolar cells and avoid contacting others, providing a basis for the formation of cone-specific connections in the IPL.

[Key words: primate, in vitro preparation, visual acuity, color vision, parvocellular pathway, coverage factor]

The central retina of the primate contains a specialized vertical pathway that links a single cone photoreceptor through a bipolar cell to a single ganglion cell. The existence of this private line from photoreceptor to ganglion cell was first inferred from Golgi preparations (Polyak, 1941; Boycott and Dowling, 1969; Kolb, 1970) and has recently been confirmed by electron microscopic reconstruction of single cells (Kolb and Dekorver, 1991; Calkins et al., 1992). The ganglion cells in this pathway were termed midget ganglion cells because their dendritic trees were found to bc only about $5-10 \mu \mathrm{m}$ in diameter.

The midget cells almost certainly belong to the class of physiologically identified, color-opponent ganglion cells (for reviews, see Shapley and Perry, 1986; Kaplan et al., 1990). Color-opponent cells generally have very small receptive fields (DeMonasterio and Gouras, 1975), and midget cells have the smallest dendritic fields of all primate ganglion cells. The midget cells provide the major projection to the parvocellular layers of the dorsal lateral geniculate nucleus (Leventhal et al., 1981; Perry et al., 1984), where cells with small, color-opponent receptive fields are recorded (e.g., Wiesel and Hubel, 1966; Creutzfeldt et al., 1979; Derrington et al., 1984; for a review, see Lennie and D'Zmura, 1988). Lesions confined to the parvocellular layers, or direct destruction of parvocellular-projecting ganglion cells, compromise color vision, peak visual acuity, and the transmission of high-spatial- and low-temporal-frequency signals (Merigan and Eskin, 1986; Merigan, 1989; Schiller et al., 1990; Merigan et al., 1991; Lynch et al., 1992). The midget cell population is thus implicated as a substrate both for the spatial resolution limit across the visual field and for color vision (Shapley and Perry, 1986; Lennie et al., 1991).

Despite the presumed importance of midget ganglion cells in primate vision, fundamental questions about their anatomical urganization remain unanswered. In both human and macaque, it has been concluded that midget ganglion cells form a single population that shows a characteristic increase in dendritic field size with increasing eccentricity (Perry et al., 1984; Rodieck et al., 1985; Watanabe and Rodieck, 1989; Dacey and Petersen, 1992). These studies all agree on a further subdivision of the midget cells into two distinct populations that stratify in either the inner or outer portion of the inner plexiform layer (IPL) and presumably correspond, respectively, to ON- and OFF-center types. However, it has also been reported that human midget 
cells remain small (and presumably transmit signals from single cones) far into the retinal periphery and that larger, midget-like cells are present in central retina (Kolb et al., 1992). Since a number of distinct color-opponent cell types have been distinguished physiologically (DeMonasterio and Gouras, 1975), such larger field midget-like cells could, if present, represent an anatomically and functionally distinct population of parvocellularprojecting ganglion cells.

A second question concerns the relationship of midget cell density to achromatic spatial acuity. On the one hand, there is evidence in macaque that, from peripheral to central retina, midget cells make up a constant fraction of the ganglion cell population, about $80 \%$ (Perry et al., 1984). This estimate has been used in calculations of cell density and of the spatial resolution limit of the midget cell mosaic as a function of eccentricity (Thibos et al., 1987; Lennie et al., 1990; Merigan and Katz, 1990; Wässle and Boycott, 1991). From these calculations it has been concluded that the intercell spacing of midget cells may set the limit on spatial acuity for both human and macaque in the retinal periphery. On the other hand, the actual dendritic overlap and intercell spacing of midget cells have never been directly observed, and there is indirect evidence to suggest that the proportion of midget cells changes dramatically as a function of eccentricity (Connolly and Van Essen, 1984; Schein and DeMonasterio, 1987; Dacey and Petersen, 1992). It has also been pointed out that certain measures of human spatial resolution may be subject to sampling artifacts that could lead to an overestimation of acuity limits in peripheral vision (Williams and Coletta, 1987; Anderson et al., 1991). Thus, a further assessment of the potential link between the anatomy of midget cells and acuity requires an understanding of the human midget cell mosaic, together with a measurement of human spatial resolution in the periphery that is free of sampling artifacts.

A final question concerns the neural basis for color opponency. Both anatomical and physiological evidence has recently converged to suggest that cone-specific connections arise at the level of the IPL (Reid and Shapley, 1992). Horizontal cells contact all cone types nonselectively (Boycott et al., 1987; Wässle ct al., 1989a), and do not convey chromatically sclective signals (Dacheux and Raviola, 1990). However, midget bipolar cells contact single cones even in the retinal periphery and could thereby transmit a cone-specific signal to the midget ganglion cells (Boycott and Wässle, 1991). For example, red ON-center cells could directly contact only the submosaic of midget bipolar cells that receive input from red cones, while neighboring green ON-center cells would overlap and selectively connect to the midget bipolar cells that receive from green cones (Wässle and Boycott, 1991). This hypothesis suggests that the shape and overlap of midget cell dendritic trees could provide evidence as to whether such selective connections exist.

In the present study I have used intracellular injection techniques in an in vitro preparation of the human retina (Dacey and Petersen, 1992) to address the above questions. It was found that midget ganglion cells form only two distinct cell mosaics. These stratify broadly in either the inner or outer portions of the IPL, and presumably correspond to ON- and OFF-center types, respectively. Midget cell dendritic trees display nonoverlapping territories with a coverage for both the inner and outer mosaics of no more than 1. Estimates of cell density suggest that the midget cell population does not make up a constant proportion across the retina, but rather increases from $\sim 45 \%$ of total ganglion cells in retinal periphery to $\sim 95 \%$ in the central retina. Anatomical resolving power, calculated from midget cell spacing, closely matches a recent measure of human achromatic spatial acuity (Anderson et al., 1991), from $\sim 6^{\circ}$ to $55^{\circ}$ eccentricity. Over this eccentricity range, midget cell dendritic trees arborize into multiple, small clusters of high dendritic density, suggesting that peripheral midget cells make selective contact with a limited submosaic of midget bipolar cells within their dendritic fields.

\section{Materials and Methods}

In vitro isolated retina. The retinal preparation and the intracellular injection technique were developed to study the morphology of neurons in the macaque and other mammalian retinas (Vaney, 1985, 1986; Dacey, 1988; Watanabe and Rodieck, 1989). These methods were applied with little modification to human retinas that were dissected from eyes obtained 90-120 min after death. Eyes $(n=46$; age range, 16-82 years) were accepted from donors to the Lions Eye Bank at the University of Washington. Eyes were taken both from cornea donors and from donors whose eyes were medically unsuitable for cornea donation. No obvious differences in the data were observed over the range of ages sampled and this variable was not further studied.

To isolate the retina, the eye was sectioned with a razor blade at the corneoscleral junction and the vitreous was drained from the eye cup. The eye cup was then placed in a continuously oxygenated tissue-culture medium (Ames, Sigma) at room temperature, and the retina was dissected free of the sclera and choroid and then freed from the eye cup by cutting the optic nerve head. Isolated retinas were left in the oxygenated medium for a $1-2 \mathrm{hr}$ "recovery" period and subsequently placed flat, photoreceptor side down, in a superfusion chamber on the stage of a light microscope. Each retina was maintained in the chamber for $\sim 8-$ $10 \mathrm{hr}$ with no apparent detcrioration in morphology. At the end of an experiment the retina was removed from the chamber and fixed for $2-$ $3 \mathrm{hr}$ in a phosphate-buffered fixative ( $2 \%$ glutaraldehyde, $2 \%$ paraformaldehyde or $4 \%$ paraformaldehyde; $0.1 \mathrm{M}, \mathrm{pH} 7.4$ ). Intracellular injection experiments were typically performed consecutively on both the left and right eyes of a pair. Because experiments could be conducted on only one retina at a time, the retina from the fellow eye was maintained free floating in oxygenated medium during the course of the first experiment.

Intracellular injection and histology. Retinal cells were stained in vitro with the fluorescent dye acridine orange and observed under blue episcopic illumination. Intracellular injections were made into the fluorescing cells under direct microscopic control with beveled, microcapillary glass electrodes. Electrodes were filled with a solution of Lucifer yellow ( $2 \%$; Aldrich) in $20 \mathrm{~mm}$, pH 7.0 MOPS buffer (Sigma), and either rhodamine-conjugated horseradish peroxidase (HRP) ( 4\%; Sig$\mathrm{ma})$ or Neurobiotin ( $4 \%$; Vector Labs). HRP-filled electrodes were beveled to a resistance of $\sim 40 \mathrm{M} \Omega$. Neurobiotin-filled electrodes were beveled to a resistance of $\sim 80 \mathrm{M} \Omega$ or left unbeveled $(\sim 120 \mathrm{M} \Omega)$. Lucifer yellow fluorescence in the electrode and the acridine orange fluorescence of the ganglion cells were observed with the same excitation filter (410$490 \mathrm{~nm}$; barrier filter, $515 \mathrm{~nm}$ ), permitting direct observation of the electrode tip as it penetrated a cell. Lucifer yellow was passed into an impaled cell with 1-2 nA negative current for $30 \mathrm{sec}$ to confirm a successful penetration and to identify the cell type being injected or to determine its depth of stratification in the inner plexiform layer. Rhodamine-conjugated HRP was subsequently passed into the cell with 1$5 \mathrm{nA}$ positive current for 1-3 min and was observed directly with a green filter (excitation filter, $545 \mathrm{~nm}$ longpass; barrier filter, $590 \mathrm{~nm}$ ). Neurobiotin was injected with $0.1-0.5 \mathrm{nA}$ positive current for $30-60$ sec but, as it was unconjugated to a fluorescent tag, could not be observed passing into the cell.

For the cells that were injected with rhodamine-conjugated HRP, the HRP was demonstrated using diaminobenzidine (DAB) as the chromogen. Retinas were incubated in the DAB solution $(0.1 \%$ in $0.1 \mathrm{M}$ phosphate buffer, pH 7.4) for 5 min. $\mathrm{H}_{2} \mathrm{O}_{2}(3.0 \%)$ was then added to DAB solution $(30 \mu \mathrm{l}$ in $30 \mathrm{ml})$ and agitated for $3-4 \mathrm{~min}$. Retinas were rinsed in buffer, whole-mounted on gelatin-coated slides, and air dried for a few hours. The tissue was then dehydrated in a graded alcohol series, cleared in xylene, and coverslipped in DPX. When the retina was mounted in this way there was little shrinkage in the plane of the retina $(\sim 2 \%)$. Radial shrinkage was $\sim 60 \%$; the inner plexiform layer, for example, was reduced from $\sim 25-30 \mu \mathrm{m}$ thickness (measurements 


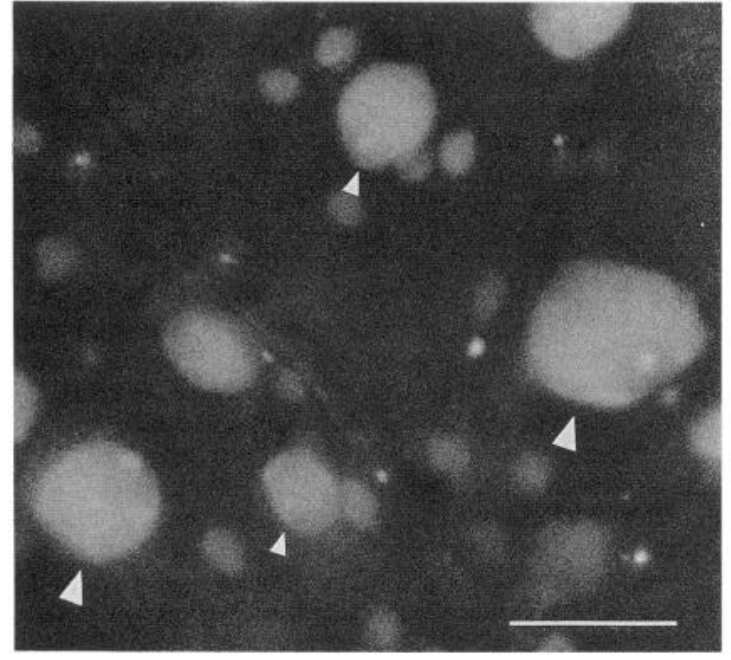

Figure 1. Ganglion cells stained with the fluorescent dye acridine orange in an in vitro whole-mount preparation of the isolated human retina. Plane of focus is on the ganglion cell layer in the retinal periphery. The distinctive soma size range of midget ganglion cells permitted them to be reliably targeted for intracellular injection. The small arrowheads indicate the cell bodies of two midget ganglion cells. The large arrowheads indicate the cell bodies of the other common ganglion cell class, the parasol cells. The larger cell body of each pair tends to belong to the cell type with dendrites that stratify in the inner portion of the IPL, the presumed ON-center cells. Scale bar, $25 \mu \mathrm{m}$.

taken from in vitro, acridine-stained retinas) to about $\sim 10-12 \mu \mathrm{m}$ after dehydration.

The injected Neurobiotin was revealed by an HRP reaction product using the Vector $\mathrm{ABC}$ protocol (Vector, Elite kit). Retinas fixed in $4 \%$ paraformaldehyde were first placed in $0.5 \%$ Triton X-100 (in $0.1 \mathrm{M}$ phosphate buffer, $\mathrm{pH} \mathrm{7.4)}$ at room temperature for $3 \mathrm{hr}$, and then incubated in buffer containing the Vector avidin-biotin-HRP complex for $3 \mathrm{hr}$. The tissue was then rinsed in buffer for $1 \mathrm{hr}$ and standard HRP histochemistry was performed using DAB as the substrate, as described above for the HRP reaction. Triton-treated retinas were easily damaged by dehydration and were therefore whole-mounted in an aqueous solution of glycerol and polyvinyl alcohol (Heimer and Taylor, 1974). The mountant partially dries to a water-retaining, rubbery film that provides reasonable tissue clarity and permits long-term storage and analysis of the retinas with little or no shrinkage.

Conversion to angular eccentricity in degrees. In order to convert distance from the fovea in millimeters to degrees of visual angle, the nonlinear conversion of Drasdo and Fowler (1974) was used. In their schematic human eye, the distance-to-angle conversion is $275 \mu \mathrm{m} / \mathrm{de}$ gree in the fovea and decreases to $\sim 135 \mu \mathrm{m} /$ degree at $90^{\circ}$ eccentricity. The nonlinear relationship between retinal distance and visual angle (Fig. 2 in Drasdo and Fowler, 1974) is well fitted by the second-order polynomial equation $y=0.1+3.4 x+0.035 x^{2}(R=1.0)$, where $y$ is eccentricity in degrees and $x$ is eccentricity in millimeters. Conversion to angular eccentricity in the central retina is complicated by the lateral displacement of ganglion cells from the inner segments of the photoreceptors from which they receive input. Therefore, ganglion cell eccentricity was converted to inner segment eccentricity for all cells within $3 \mathrm{~mm}$ of the fovea. The lengths of photoreceptor axons (Henle fibers) have been measured directly for the macaque retina (Perry and Cowey, 1988; Schein, 1988), but in the human retina it has been predicted that Henle fibers are somewhat longer than in the macaque (Curcio and Allen, 1990). Direct measurements of human Henle fiber lengths using the method of Schein (1988) (C. Curcio, personal communication, unpublished observations) bear out this prediction, and were used to generate the following equation to correct for ganglion cell displacement: $y=-0.020+0.46 x+0.20 x^{2}(R=1.0)$, where $y$ is inner segment eccentricity in millimeters and $x$ is ganglion cell eccentricity in millimeters.

Data analysis. For each retina the location of every injected ganglion cell relative to the foveal center was recorded. Each cell was photographed, and a simple camera lucida tracing of the dendritic tree (total magnification, $480 \times$ or $960 \times)$ and an outline of the cell body at higher magnification $(1940 \times)$ were made. A measure of dendritic field diameter was acquired for the intracellularly filled ganglion cells by tracing a convex polygon around the perimeter of the traced dendritic tree. The area of this polygon was then calculated by entering the outline into a computer via a graphics tablet. Dendritic field diameter was expressed as the diameter of a circle with the same area as that of the polygon. Cell body area was similarly expressed in terms of an equivalent diameter.

Measurements of the depth of stratification in the inner plexiform layer of the midget cell dendritic trees were obtained in two cases for overlapping pairs of midget cells; one member of each pair branched in the inner portion of the IPL and the other branched in the outer portion. A fifth cell, an outer branching midget cell, was also included. All cells were located in peripheral, temporal retina, the two cell pairs at 13 and $14 \mathrm{~mm}$ eccentricity and the single cell at $15.5 \mathrm{~mm}$ eccentricity. Tissue pieces containing the cells were cut from reacted retinas prior to mounting and were embedded in plastic resin (Medcast). Vertical sections through the dendritic fields were cut at $10 \mu \mathrm{m}$ with a glass knife and mounted on slides in serial order. A detailed camera lucida tracing of each section was made (total magnification, 1940 $\times$ ), that indicated the outer and inner borders of the inner plexiform layer and all HRPlabeled dendritic segments. Each of these tracings was then placed on a graphics tablet and overlain with a grid of lines orthogonal to the retinal layers and spaced $5 \mu \mathrm{m}$ apart. The locations of the inner and outer borders of the inner plexiform layer, and of the labeled dendrites that intersected each grid line, were then entered into the computer. Measurements were made on every serial section that contained labeled dendrites. The relative depth of stratification (expressed as a percentage of the total thickness of the inner plexiform layer) was then calculated at each point of measurement. A histogram displaying all the depth measurements was then compiled.

The dendritic trees of the midget cells displayed distinct regions of high density or "clusters," surrounded by regions of low density or "holes." To quantify the tendency toward dendritic clustering, contour plots of the midget dendritic tree densities were made using commercial software (Transform, Spyglass Inc.) and a Macintosh computer. Camera lucida tracings of the branching patterns of dendritic trees were converted to PICT files at $150 \mathrm{dpi}$ using a Microtech Gray Scale Scanner. Using Transform, the PICT image of the dendritic tree was converted to an array of 8-bit data values. Before generating a contour plot the data set was smoothed to eliminate the sharp edges created by individual dendrites. The data smoothing was accomplished by averaging the value at a given point in the data set with those of its eight immediate neighbors and then assigning the average value to each of the points. The smoothing procedure was repeated 15 times for each dendritic tree and a gray scale image of the smoothed data set was generated. Finally, contour lines were overlaid on this image at $30 \%$ and $70 \%$ of maximal image density for each of the dendritic trees. The areas bounded by the $70 \%$ contour lines were defined as clusters of high dendritic density and the area of each cluster was measured.

\section{Results}

\section{An in vitro preparation of the human retina}

The appearance of cells in the isolated human retina, when maintained in oxygenated Ames medium at room temperature, was very similar to that of cells observed in the isolated macaque monkey retina maintained in the same way (Dacey, 1989a, 1990; Watanabe and Rodieck, 1989). Acridine orange intensely stained the basophilic material of the cell bodies in the ganglion cell layer against an unstained background (Fig. 1); fluorescent cytoplasm surrounded an unstained nucleus containing an intensely stained nucleolus. With some practice it was possible to distinguish reliably a number of morphologically distinct ganglion cell types on the basis of soma size, shape, and subtle details of the acridine fluorescence. Dendritic field diameters were determined for a sample of 1225 intracellularly filled retinal ganglion cells, including midget, parasol, and many other ganglion cell types (e.g., Dacey, 1993). Cells that were included in this database showed uniform staining that ended abruptly 

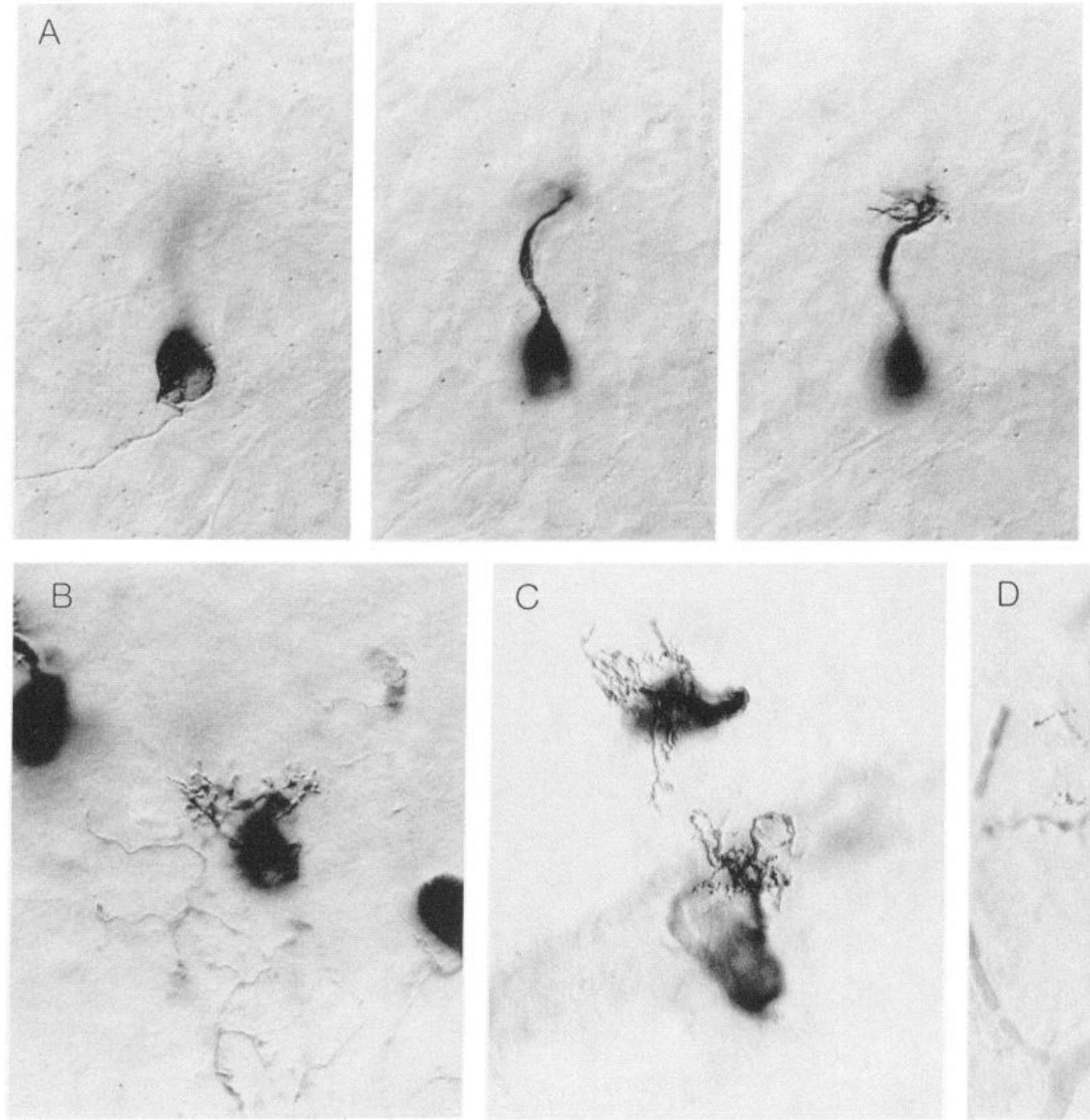

C
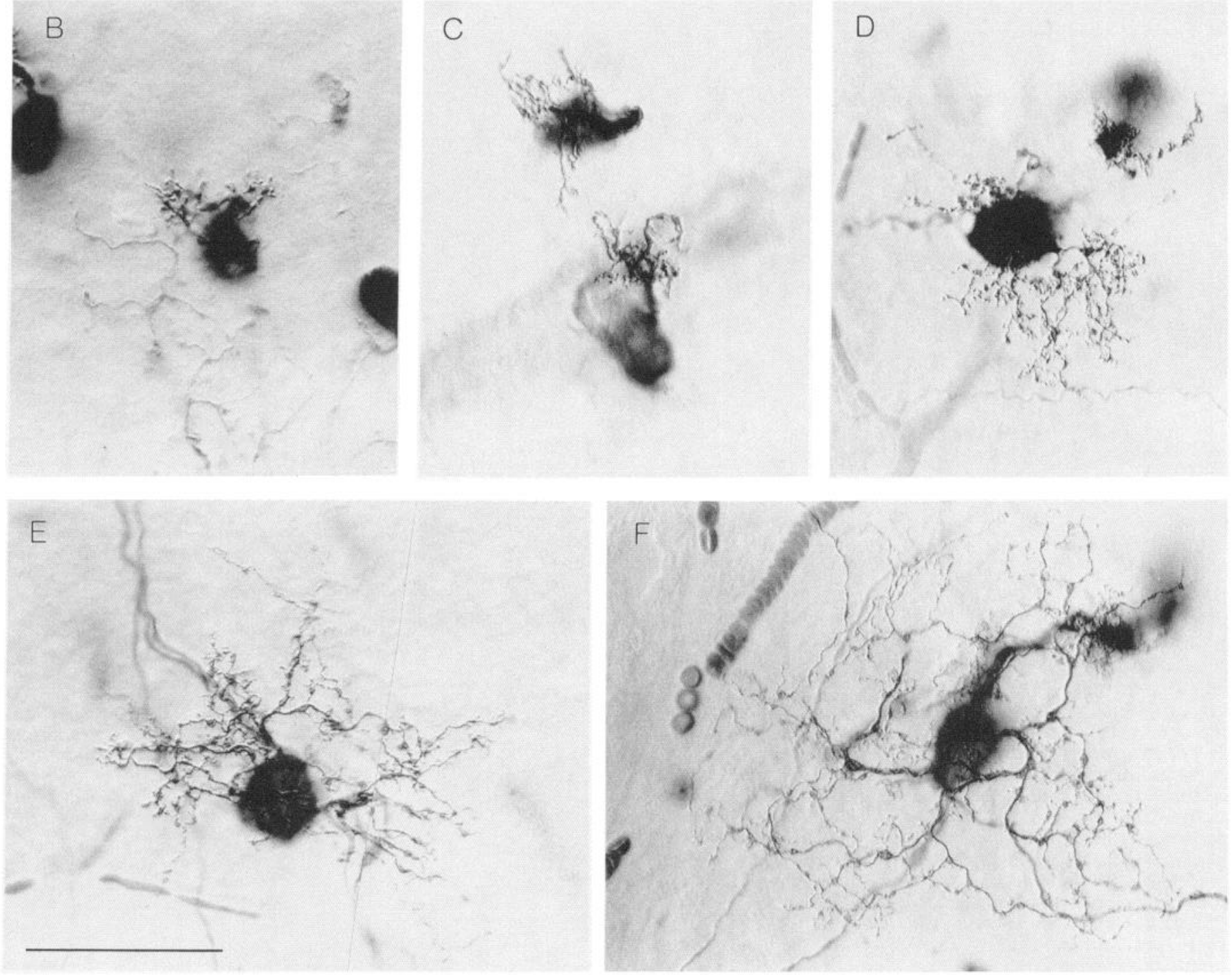

Figure 2. Intracellularly stained human midget ganglion cells. $A$, Foveal cell, $0.8 \mathrm{~mm}$ eccentricity, temporal retina. The four panels show successive planes of focus from cell body and axon (left) to terminal dendritic arbor (right). B, Near retinal periphery, $2.4 \mathrm{~mm}$ eccentricity, temporal retina. $C$, Near retinal periphery, $3.2 \mathrm{~mm}$ eccentricity, upper retina. Two cells are shown; the upper cell is partly out of the plane of focus. $D$, Mid retinal periphery, $7.8 \mathrm{~mm}$ eccentricity, temporal retina. $E$, Retinal periphery, $9 \mathrm{~mm}$ eccentricity, upper retina. $F$, Far retinal periphery, $16 \mathrm{~mm}$ eccentricity, nasal retina. Scale bar, $50 \mu \mathrm{m}$ (for all panels). 
Figure 3. Identification of midget ganglion cells by dendritic field diameter. Dendritic field diameter of all intracellularly stained ganglion cells is plotted as a function of retinal eccentricity. Midget ganglion cells were identified qualitatively by their distinctive dendritic morphology. When dendritic field diameter of all cells was plotted, the midget cells, as expected, formed a distinct cluster that showed little overlap with the nonmidget ganglion cells. The few midget and nonmidget cells that did show overlapping dendritic field diameters (in the retinal periphery) are actually located in different retinal quadrants: the largest midget cells in the retinal periphery reside in the temporal retinal quadrant whereas the smallest nonmidget cells reside in the nasal retinal quadrant.
Figure 4. Dendritic field size as a function of retinal eccentricity for human midget ganglion cells. $A$, Scatterplot of field diameter (in $\mu \mathrm{m}$ ) against eccentricity (in $\mathrm{mm}$ ) from the fovea. Nasal cells (solid circles) are smaller than cells from the temporal, upper or lower retinal quadrants. Cells from the central $2 \mathrm{~mm}$ show a relatively constant dendritic field size of 5-10 $\mu \mathrm{m}$ diameter. $B$, Scatterplot of field diameter converted to minutes of arc plotted against eccentricity converted to degrees of visual angle. See Materials and Methods for calculations used to make conversion from distance in millimeters to degrees of visual angle. Equation for the curve fit to the data is a third-order polynomial: $y=2.1+0.058 x+0.022 x^{2}$ $-0.00022 x^{3}$.
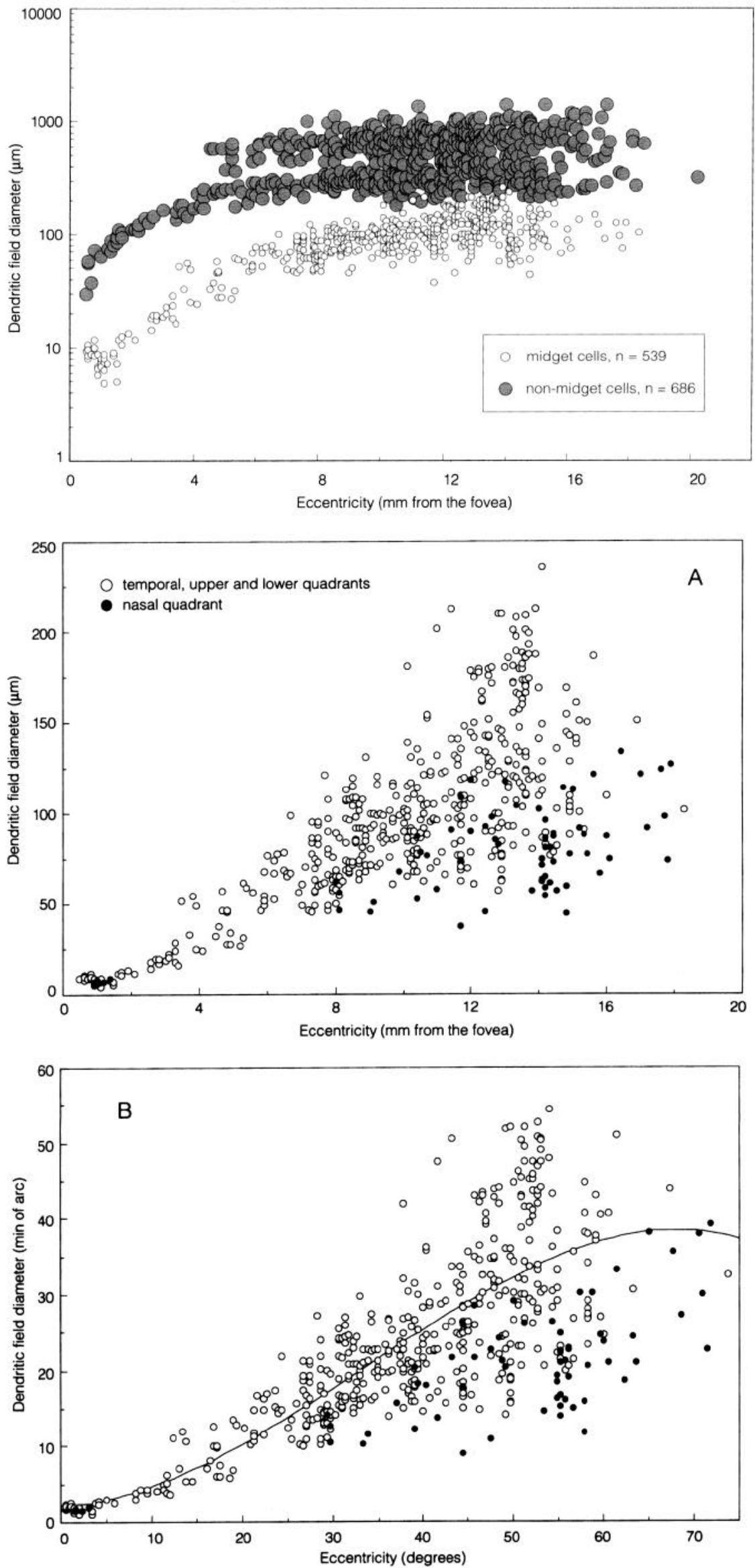
at the distal ends of the dendrites and appeared completely stained by the HRP or Neurobiotin injection.

\section{Identification of midget ganglion cells}

Intracellularly filled midget ganglion cells, as characterized in the macaque retina (Watanabe and Rodieck, 1989) and observed in Golgi studies of the human retina (Rodieck et al., 1985; Kolb et al., 1992), were easily recognized as the dominant cell group in our sample of injected cells (Fig. 2). With practice it was possible to recognize the cell bodies of midget cells and fill them at most eccentricities. Injections of midget cells were technically difficult, however, in the central $2-4 \mathrm{~mm}$ of retina. In this region the increased thickness of the inner limiting membrane, optic fiber layer, and ganglion cell layer, together with the small size of the ganglion cell bodies, made a successful electrode penetration difficult and the sample of recovered cells was consequently lower than in the retinal periphery.

The midget cells had small cell bodies, and dendritic trees that were extremely small compared to the dendritic trees of all other morphologically characterized ganglion cells. By this qualitative feature we identified 539 midget cells from the total sample of 1225 filled cells. The midget cells appeared to comprise a single morphologically distinct group and, as shown in previous studies of both human and macaque, increased in dendritic field size with retinal eccentricity (Fig. 2). A scatterplot of dendritic field diameter for all stained ganglion cells as a function of retinal eccentricity indicated a clear separation between those cells classified as midgets and all other cells between 0 and $9 \mathrm{~mm}$ eccentricity (Fig. 3). Between 9 and $16 \mathrm{~mm}$ eccentricity a few of the largest midget cells (dendritic field diameter of 180-225 $\mu \mathrm{m}$ ) overlapped with the smallest nonmidget cells. However, even for these few cells there was not a true overlap because the smallest nonmidget cells were from the nasal retina, where cell density is high and ganglion cell dendritic trees are relatively small, and the largest midget cells were from temporal, upper and lower retina, where cell density is much lower and dendritic trees are relatively large. Thus, all of the cells that were initially identified as midget cells by their appearance also formed a single, distinct group on the basis of dendritic ficld diamcter in a given retinal quadrant.

\section{Midget dendritic field size range}

The relationship between dendritic field size and retinal eccentricity for the midget cells was not linear. In the central retina, from $\sim 0.25$ to $2.0 \mathrm{~mm}\left(0-6^{\circ}\right)$ eccentricity, the dendritic tree was composed of a single, primary dendrite that terminated in a small arbor between 5 and $10 \mu \mathrm{m}$ in diameter (Figs. 4, 5). Although the arbor size was somewhat variable, there appeared to be no systematic increase in arbor size over this eccentricity range. Between 2 and $7 \mathrm{~mm}\left(6-25^{\circ}\right)$ eccentricity, the dendritic tree showed a steep 10-fold increase in dendritic field size (Fig. 4). Over this range dendritic field diameter exceeded soma diameter. The dendritic arbor also became more complex, showing second- and third-order branches that often arborized into multiple clusters within the dendritic ficld (Figs. 6,7). The tendency of the midget cell dendritic tree to form regions of high and low density, and its possible significance, are examined below. Between 7 and $20 \mathrm{~mm}\left(25-75^{\circ}\right)$ the dendritic tree showed a more gradual two- to threefold increase in size while the dendritic tree retained its characteristic morphology (Fig. 8).

A distinct feature of the midget cell population was the large scalter in field sizes in the retinal periphery. As observed in the

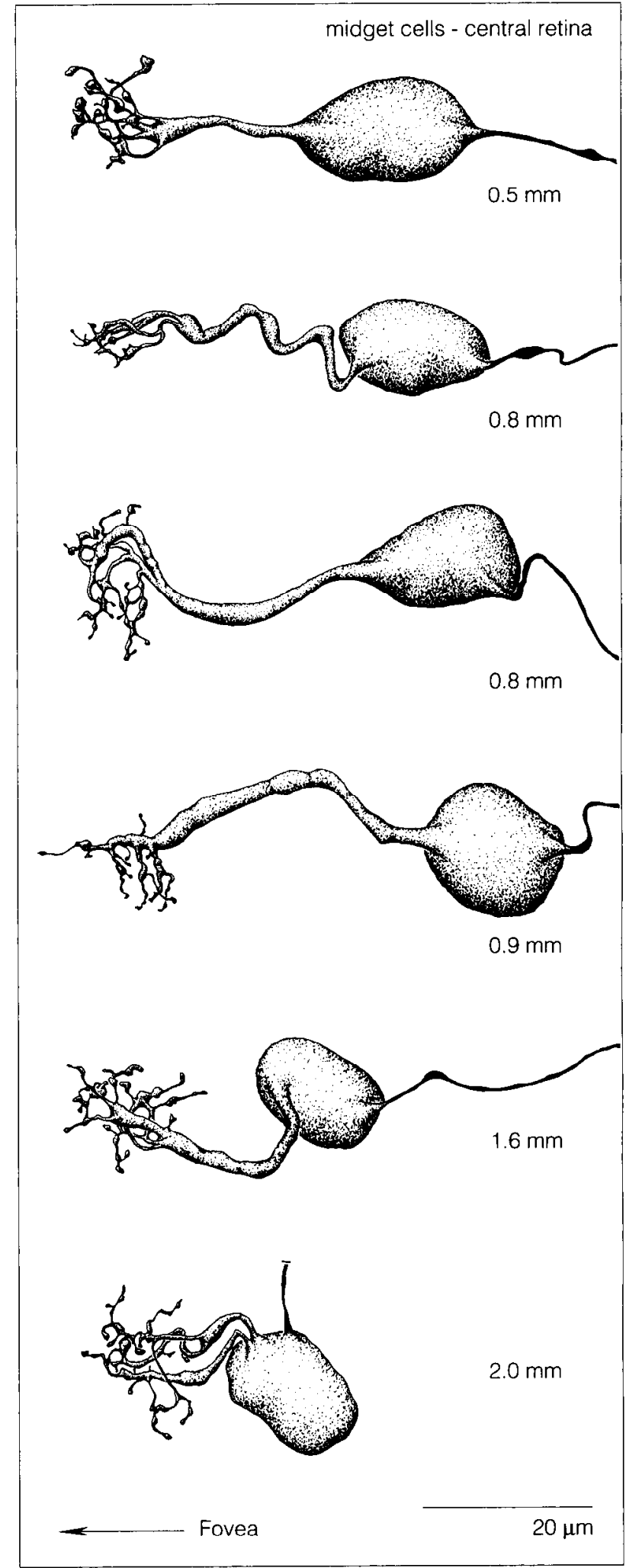

Figure 5. Dendritic morphology of midget ganglion cells within $2 \mathrm{~mm}$ of the fovea. Midget cells from the central retina give rise to a single primary dendrite that branches into a single, compact arbor of fine branchlets and varicosities. The cell shown at $2 \mathrm{~mm}$ eccentricity (bottom) gives rise to two major dendrites that terminate in a slightly larger dendritic field than more centrally located cells. Retinal eccentricity is given for each cell. 
Figure 6. Dendritic morphology of midget ganglion cells from the near retinal periphery. From 2 to $2.5 \mathrm{~mm}$ eccentricity the dendritic field size of midget ganglion cells begins to increase. The larger dendritic arbors display a nonuniform distribution of dendritic branches within the dendritic field; terminal branches often arborize into multiple clusters within the dendritic field. The dendritic clusters surround regions that show a very low density of dendritic branches. Retinal eccentricity and level of stratification (inner or outer) in the IPL are given for each cell.

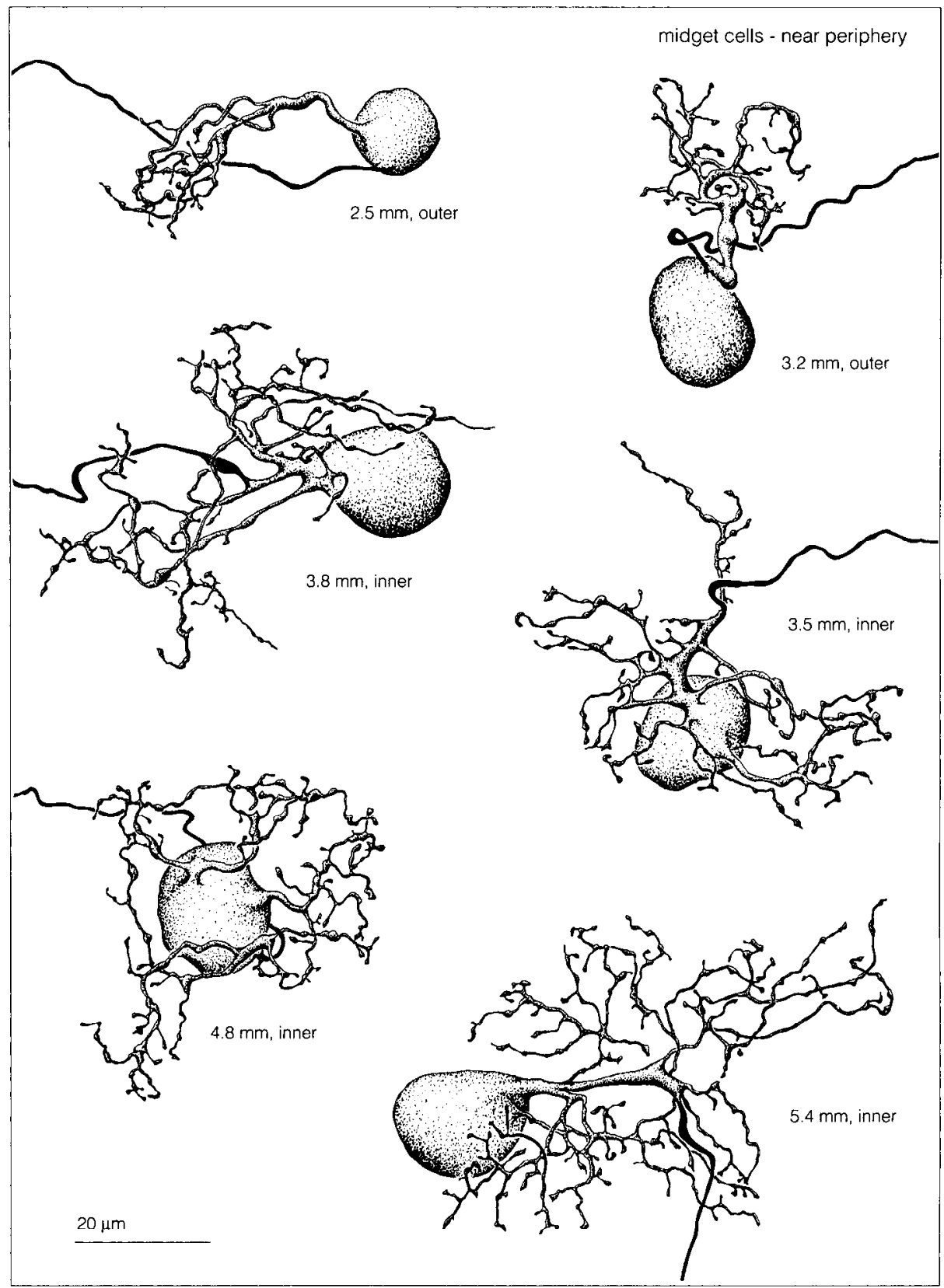

branching dendritic trees. This is illustrated for two neighboring midget cells in Figure 9. A cell with a smaller, more densely branched tree was filled adjacent to a cell with a larger tree that branched sparsely in multiple, widely spaced subfields. Evidence is presented below that this variation in dendritic tree morphology is an inherent feature of the human midget cell mosaic.

\section{Inner and outer midget cell types}

The midget ganglion cells could be divided into two cell types on the basis of their depth of stratification in the IPL, as previously found in macaque (Polyak, 1941; Perry et al., 1984; Watanabe and Rodieck, 1989). One type stratified in the inner half of the IPL and the other type in its outer half, presumably corresponding respectively to ON- and OFF-center cell types (Famiglietti and Kolb, 1976). I will refer to these two types as the inner midget and the outer midget cells, respectively.

Midget cells at eccentricities beyond $1.5 \mathrm{~mm}$ could be iden- variation in the dendritic branching patterns of cells. The largest cells at a given retinal eccentricity tended to have more sparsely proportion of the mean dendritic field size. This scatter was larger than that previously observed for either the midget or parasol ganglion cells of the macaque retina (Watanabe and Rodieck, 1989).

The variation in dendritic field size was a consequence of 


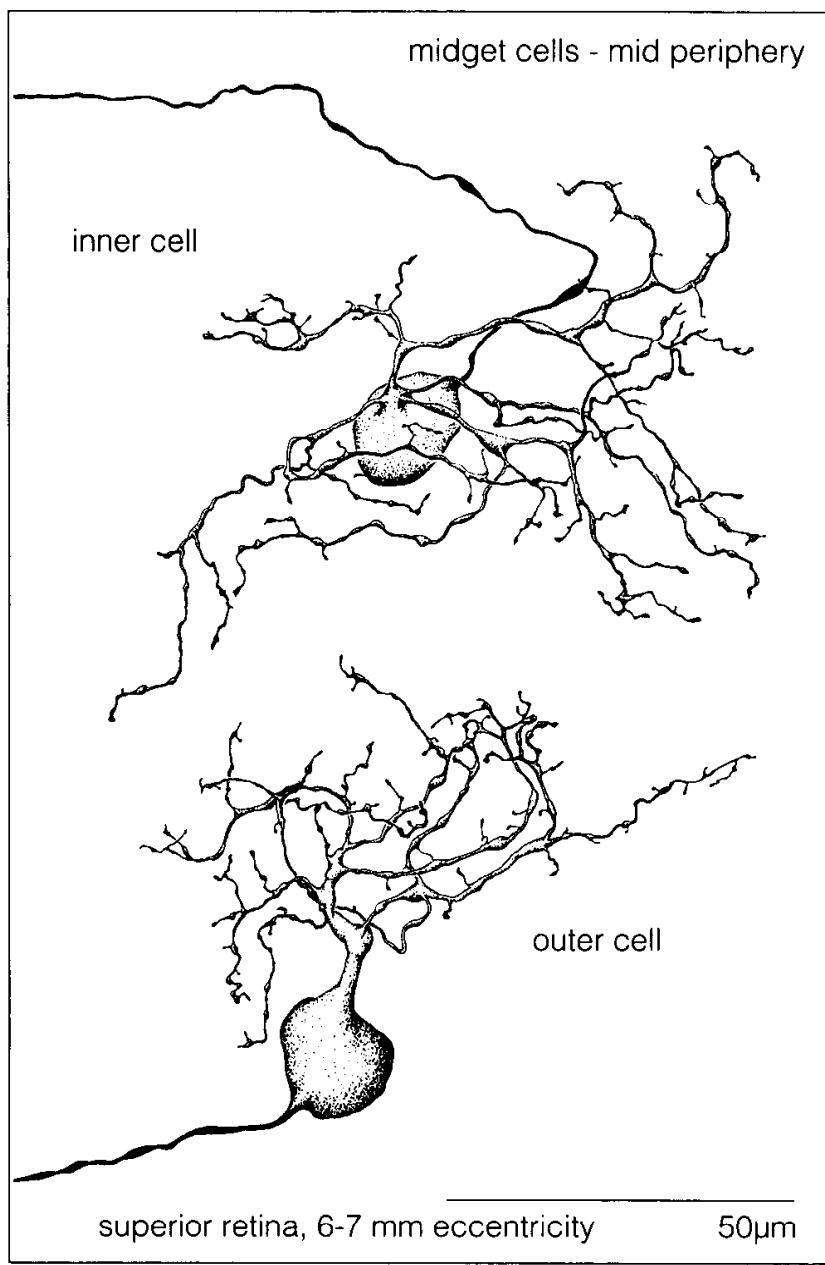

Figure 7. Midget ganglion cells from mid-peripheral retina. The cells illustrated are from the same retina, separated by about $500 \mu \mathrm{m}$ at $6-$ $7 \mathrm{~mm}$ eccentricity. At this eccentricity the midget cells reach a dendritic tified as either inner or outer cells in whole-mounts by measuring the distance from the cell body to the level of major dendritic stratification. After dehydration the IPL measured about 10-12 $\mu \mathrm{m}$ in total thickness; cells that were identified as inner midget cells tended to be stratified $\sim 2-5 \mu \mathrm{m}$ from the parent cell body, and those identified as outer cells were stratified $\sim 7-10 \mu \mathrm{m}$ from the parent cell body. Inner midget cells tended to have larger dendritic trees than outer midgets. A scatterplot of inner and outer midget dendritic field diameter as a function of retinal eccentricity showed that the population of inner midgets was on average about $30 \%$ larger in dendritic field diameter than the outer midgets (Fig. 10A). The inner midget cells also showed a slightly larger soma size than the outer midget cells (mean \pm $\mathrm{SD}$, for inner cells, $18.6 \pm 2.3 \mu \mathrm{m}$; for outer cells, $17.4 \pm 2.3$ $\mu \mathrm{m} ; p<0.0001$, Student's $t$ test).

Could the size difference between the inncr and outer midget cells be artifactual? It could be argued that the intracellular injection technique introduced a bias that favored the recovery of inner midget cells with large dendritic trees, or that some experimenter bias occurred when the cells were classified as either inner or outer types. To address these problems, intracellular injections were made into pairs of inner and outer cells with highly overlapping dendritic trees. It was possible to target overlapping inner/outer midget pairs for injection in the retinal periphery because midget cell bodies that were closely spaced, with a separation of about $25 \mu \mathrm{m}$ or less, were invariably an inner/outer cell pair with highly overlapped dendritic trees. Dendritic field sizes of clearly identified inner and outer cells could thus be compared at the same location in the same retina (Fig. $10 C)$. In 29 out of 30 inner/outer pairs, the inner cell showed

field diameter of $50-75 \mu \mathrm{m}$. Dendrites continue to show characteristic clustered branching patterns. Most cells that branch in the outer portion of the IPL display a single primary dendrite that extends vitread before arborizing.

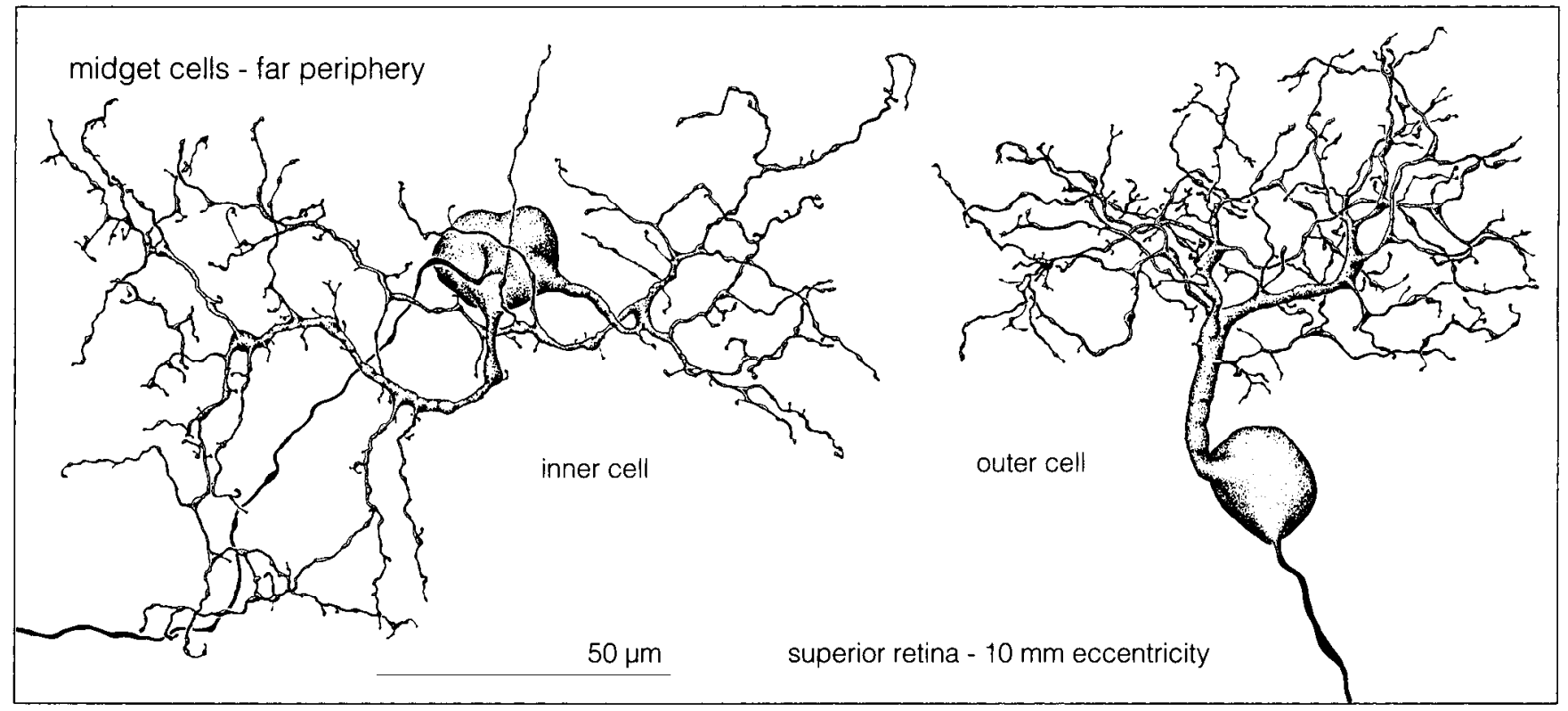

Figure 8. Midget ganglion cells from the far peripheral retina. Both cells are from a single retina, located within a few hundred micrometers of each other at $10 \mathrm{~mm}$ eccentricity. Dendritic field diameter, 75-150 $\mu \mathrm{m}$. At this eccentricity and beyond, the clustering patterns of the dendritic tree are highly variable, ranging from cells with relatively densely branching, small dendritic fields to cells with larger and more sparsely branching fields. 
Figure 9. Variable dendritic morphology of neighboring midget cells in the far retinal periphery. The two cells shown are neighboring midget cells at $13 \mathrm{~mm}$ eccentricity that both stratify at the same depth in the outer portion of the IPL. The upper cell has a smaller, more compact dendritic tree; the lower cell has a larger tree that is divided into multiple distinct and widely separated arbors.

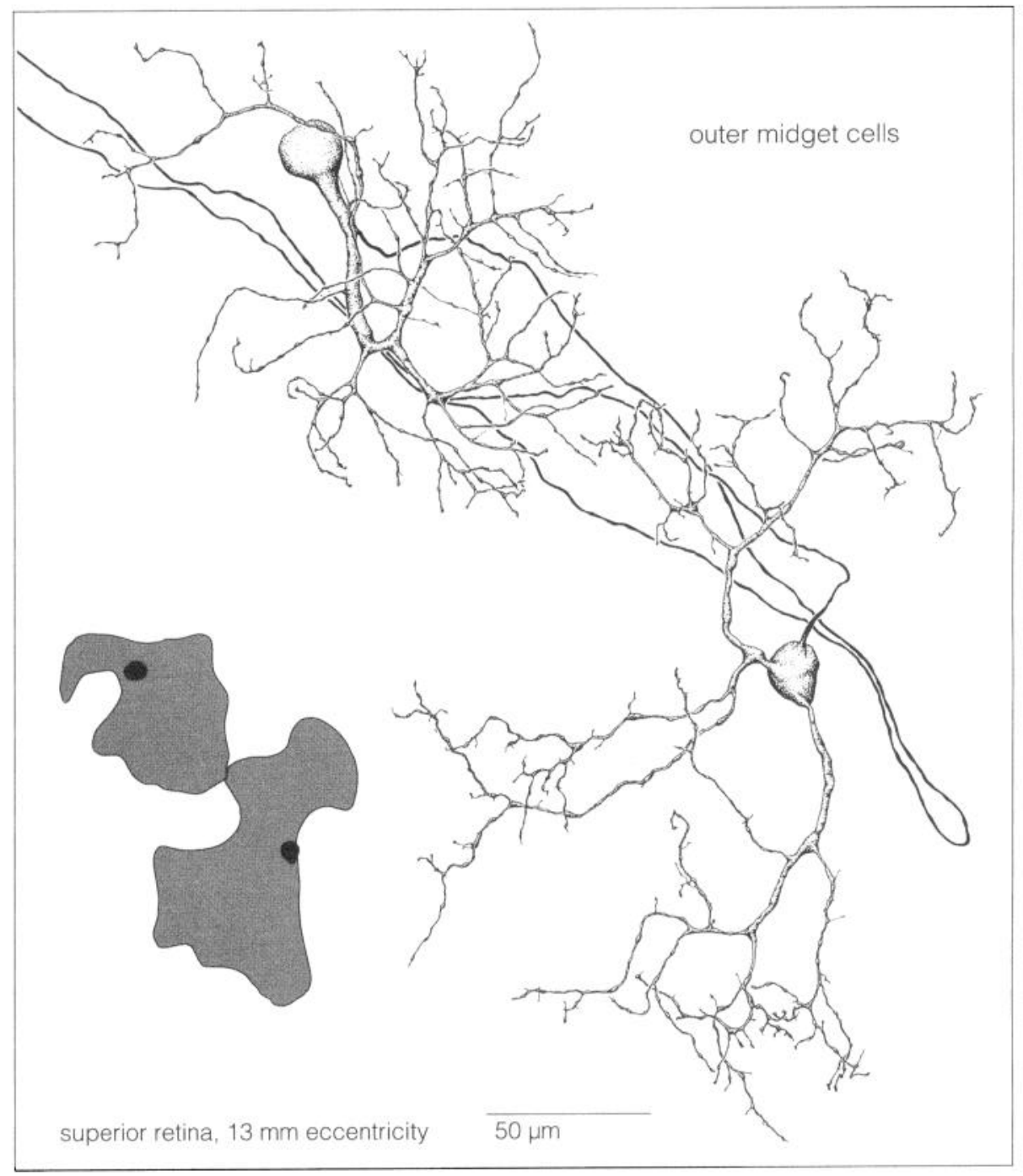

a larger dendritic field diameter (Fig. 10B). The increase in diameter ranged from $\sim 20 \%$ to $60 \%$ and averaged $\sim 30 \%$, the same as was observed in the original sample of single cells.

Both the inner and outer midget cells appeared broadly stratified over about a third of the depth of the IPL. In whole-mount preparations the dendrites of an individual cell crossed over one another at different depths. Thus, a stratified pattern of branching was observed in which two or more tiers of dendrites were clearly distinguished at distinct focal planes (Fig. 11A). The depth of stratification was measured, as described in Materials and Methods, in serial vertical sections taken through five cells (two overlapping inner/outer cell pairs and a single outer midget; all cells from the retinal periphery). For the inner midget cells, $90 \%$ of the dendritic measurements occupied about $30 \%$ of the total depth of the IPL, falling between $55 \%$ and $85 \%$ depth (inner nuclear layer cell border $=0 \%$, ganglion cell layer border $=$ $100 \%$ ) (Fig. 11B). Inner midget cells dendrites did not invade the inner $10 \%$ of the IPL. The outer midget cells extended dendritic branches to the outer border of the IPL and were stratified more broadly than the inner midgets, extending over about $40 \%$ of the IPL depth, with $90 \%$ of the dendritic measurements falling between $10 \%$ and $47 \%$ depth.

\section{Clustered dendritic morphology of nonfoveal midget cells}

Outside of the central $2 \mathrm{~mm}$, as midget cells increased sharply in dendritic field diameter, a distinct spatial nonuniformity in the branching patterns of the dendritic trees was observed. Within one dendritic tree, branches tended to form small, dense clusters, separated by regions of very low dendritic density. The degree of clustering can be appreciated by comparing the branching pattern of a midget cell with that of a parasol cell, the other common primate ganglion cell type that projects to the dorsal lateral geniculate nucleus (Leventhal et al., 1981; Perry et al., 1984). The parasol cell distributes its dendritic branches uniformly throughout the dendritic field, economically filling the available space with a relatively constant density of processes. By contrast, the midget cell shows obvious dendritic clusters and equally obvious "holes" within the dendritic field (Fig. $12 A, B)$.

The dendritic clustering appeared to be characteristic of all nonfoveal midget cells; there was great variation, however, in the pattern of the clustering from cell to cell. Some cells showed few clusters and thus appeared sparsely branched; other cells showed a number of clusters and were more densely branched. 

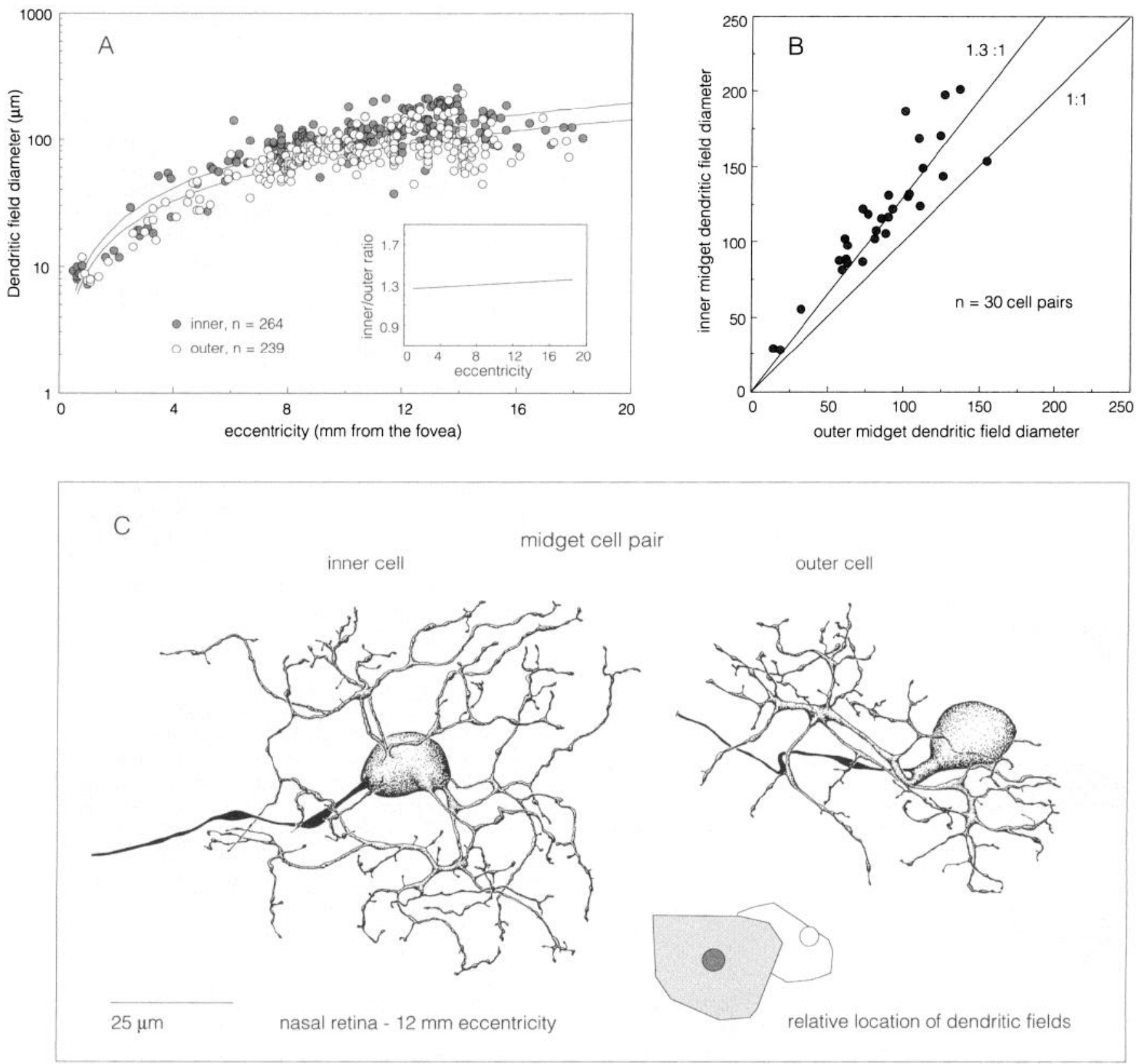

Figure 10. Dendritic field size difference between inner (presumed ON-center) and outer (presumed OFF-center) branching midget cells. $A$, Scatterplot of midget dendritic field size as a function of retinal eccentricity with cells categorized as inner (solid circles) and outer (open circles) branching types. Inset plots the inner to outer cell dendritic field diameter ratio and shows that a relatively constant ratio of 1.3 is maintained across the retina. $B$, Dendritic field diameter for inner midget cells is plotted against diameter of outer midget cells for 30 midget cell pairs with overlapping dendritic fields. A line indicating an inner:outer ratio of 1.3 was drawn through the data. $C$, An example of one inner/outer midget cell pair used for the plot shown in $B$. Both cells display are similar overall morphology but the inner cell is larger than the outer cell. The inset polygons were traced around the perimeter of the dendritic fields and show their actual spatial relationship in the retina.

There also appeared to be variation in the size of the clusters. It thus seemed possible that the midget cells could be further divided into distinct types on the basis of their clustering pattern. To test this possibility, the degree of dendritic clustering was quantified and compared for 118 well-filled midget cells. Contour plots of dendritic density were generated from digitized images of individual dendritic trees (see Materials and Methods). Dendritic clusters were defined as those regions of the dendritic tree that had a density equal to or greater than $70 \%$ of the maximum density. Dendritic "holes" were defined as that part of the dendritic field that had a density lower than $30 \%$ of maximum. The results of such an analysis for one midget and one parasol cell are shown in Figure 12. The midget cell had distinct regions of high dendritic density (clusters) and low dendritic density (holes) that clearly reflected the patchy organization of the dendritic tree illustrated in the camera lucida tracings in Figure 12, $A$ and $B$. There was also a reasonably close, but not always perfect, match between the subjectively observed number of dendritic clusters (Fig. 12A,B; approximately eight clusters) and the clusters that were arbitrarily defined by the $70 \%$ contour lines (Fig. 12C; nine clusters). By contrast, the parasol cell displayed a relatively uniform distribution of den- 

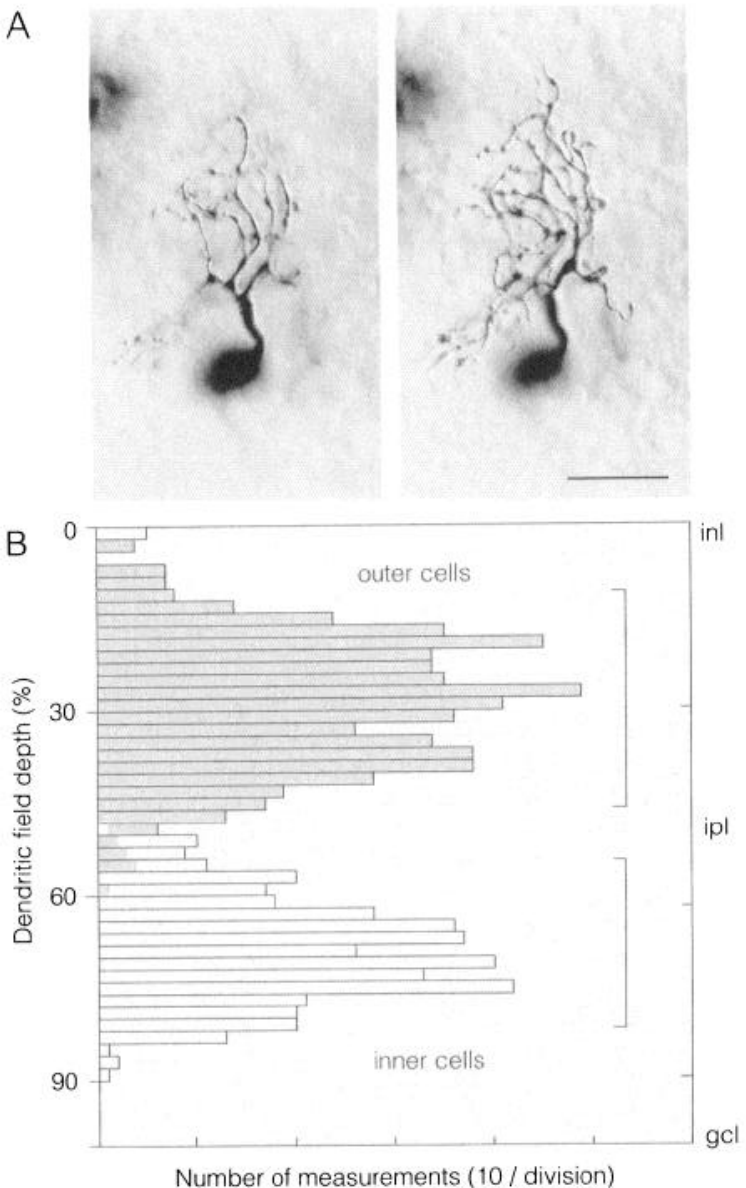

Figure 11. Depth of stratification of midget cell dendritic trees. $A$, Whole-mount view of an outer midget cell intracellularly filled with Neurobiotin. Left, Plane of focus is on dendritic branches that stratify closest to the cell body. Right, Plane of focus shifted about $6-8 \mu \mathrm{m}$ farther from the cell body; a second group of dendritic branches comes into focus. This cell thus appeared to be broadly stratified over about a third of the depth of the IPL. Scale bar, $25 \mu \mathrm{m}$. $B$, Measurements of dendritic depth sampled from vertical sections through three outer and two inner midget cells. For outer cells (shaded bars) $90 \%$ of the dendritic measurements fell within $10-47 \%$ of the total depth of the IPL, indicated by the upper bracket at the right. For inner cells (open bars) $90 \%$ of the dendritic measurements fell between $55 \%$ and $85 \%$ depth, indicated by the lower bracket. Inner midget cells did not extend terminal dendrites into the innermost $10 \%$ of the IPL.

drites such that the $30 \%$ density contour line fell near the outer border of the dendritic tree, and the contour plot did not reveal any "holes" within the dendritic field. The $70 \%$ contour line bounded a single large, more proximal part of the field where density was higher and relatively uniform.

The number of clusters per cell tended to increase with increasing distance from the fovea. All but one of six cells in the database between 2 and $3 \mathrm{~mm}$ eccentricity showed two small clusters within a larger dendritic field (Fig. 13; also see cell tracings in Fig. 6). As dendritic field size increased fourfold, from $\sim 50$ to $200 \mu \mathrm{m}$ diameter, the mean number of clusters per cell increased from two to seven (Fig. 14A,C). However, at any given eccentricity the variation in cluster number was large. For example, among the 18 midget cells with a diameter of 100 $\pm 5 \mu \mathrm{m}$ the number of clusters ranged from one to eight (mean $\pm \mathrm{SD}=4.4 \pm 1.7)$. Three other cells with comparable dendritic field areas, shown in Figure $14 D$, displayed from three to eight clusters each.

The size of the dendritic clusters was not strictly correlated with the number of clusters per cell or with the diameter of the dendritic tree. Cluster diameter (Fig. 14B) ranged from $\sim 7$ to $25 \mu \mathrm{m}$ with a mean of $13 \mu \mathrm{m}(\mathrm{SD}= \pm 3)$. For small cells, many clusters were in the same size range as those of larger cells (Fig. $14 C$ ). The variation in cluster size and number together produced a range of morphologies that could appear quite distinctive from one another. Sparsely branching cells with a few widely spaced clusters were observed at the same retinal eccentricities as densely branching cells with a larger number of closely spaced clusters.

The overall picture of midget dendritic morphology that emerges from this analysis can be summarized as follows. All cells with dendritic field diameters over 5-10 $\mu \mathrm{m}$ displayed a tendency for the dendritic tree to break up into small clustered domains. These clusters tended to increase in number with increasing dendritic field size, though the number of clusters was highly variable. At the same time the clusters tended to remain small relative to the overall size of the dendritic tree. Thus, the largest cells with relatively few clusters appeared sparsely branched, and the smaller cells with many clusters appeared to be densely branched. Midget cells could not be subdivided into distinct morphological variants by cluster diameter, cluster number, or both features combined.

\section{Midget cell mosaics}

Neither dendritic field size nor morphology provided a basis for subdividing midget cells beyond the well-established inner and outer types. If only these two types are present, then they should establish two independent mosaics of cell bodies; within each mosaic, all the dendritic trees should stratify at the same depth in the IPL. This arrangement would be equivalent to what has been found for the $\alpha-Y$ and $\beta$-X cells of the cat's retina (Wässle et al., 1981a,b) and for the magnocellular-projecting parasol cells of the macaque and human retina (Watanabe and Rodieck, 1989; Silveira and Perry, 1991; Dacey and Petersen, 1992). One property of these, as well as other identified ganglion cell mosaics (Buhl and Peichl, 1986; Dann and Buhl, 1987; Dacey, 1989a; see also Wässle and Boycott, 1991, for a review), is that the degree of overlap between neighboring dendritic trees is approximately the same across the retina, yielding a dendritic network of uniform and characteristic coverage (dendritic field area $\times$ cell density). It was difficult, however, to envision how a single inner and a single outer midget mosaic could account for such a large variation in the dendritic field size and in the branching patterns of single cells observed in the present results.

I addressed this question directly by intracellularly filling all neighboring inner or outer midget cells within a small patch of retina. To do this I took advantage of the size difference between somata of the inner and outer cells, which was visible in the retina in vitro and could be used to target either population reliably for intracellular injection. It was necessary to inject a number of cells of the same type that were nearest neighbors. This task was possible in the mid-peripheral and far peripheral retina where cell density was relatively low and the spacing of neighboring midget cells appeared very regular. Using this approach I injected 21 patches of midget cells ( 11 inner cell patches and 10 outer cell patches), containing from 4 to 30 cells/patch (mean $\pm \mathrm{SD}=6 \pm 6$ cells). Patches were located 7-12 mm from the fovea. 
A

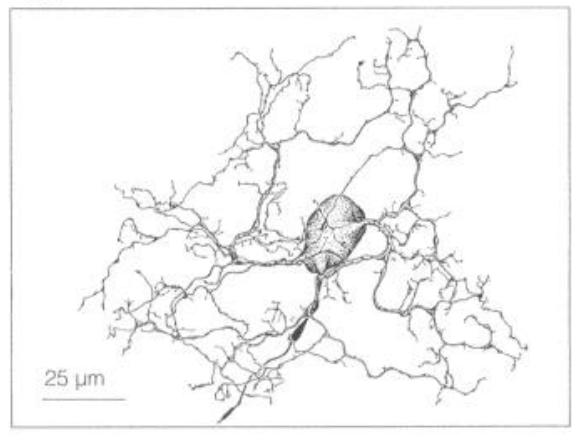

B

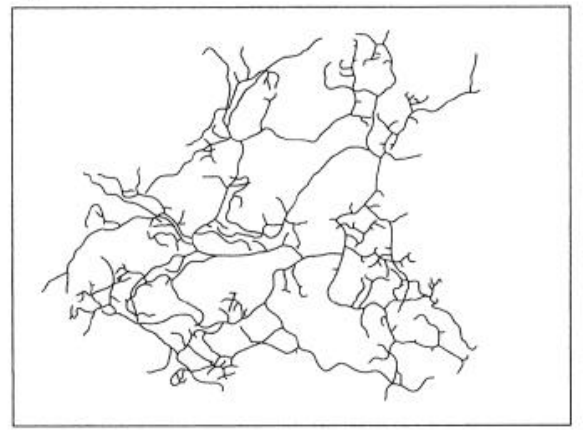

C

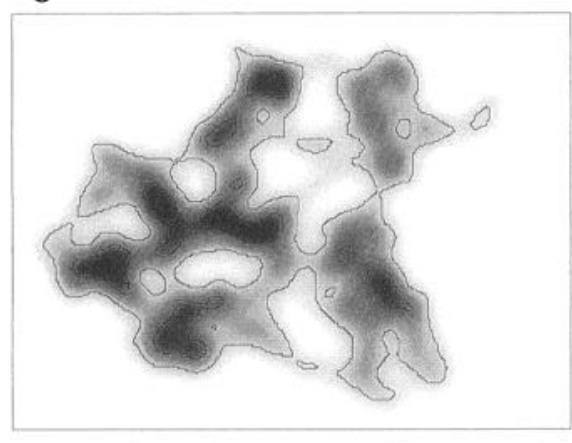

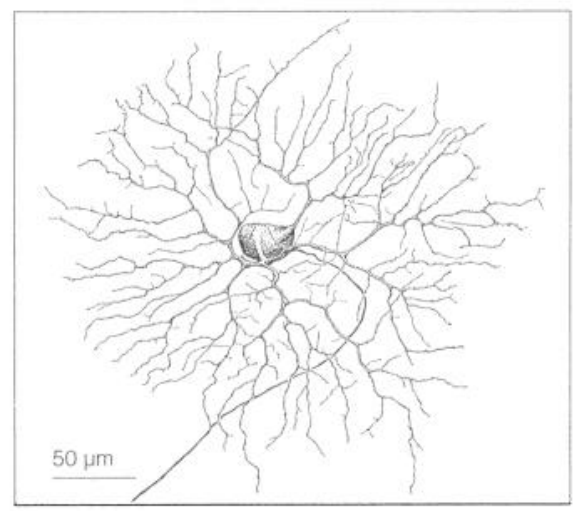
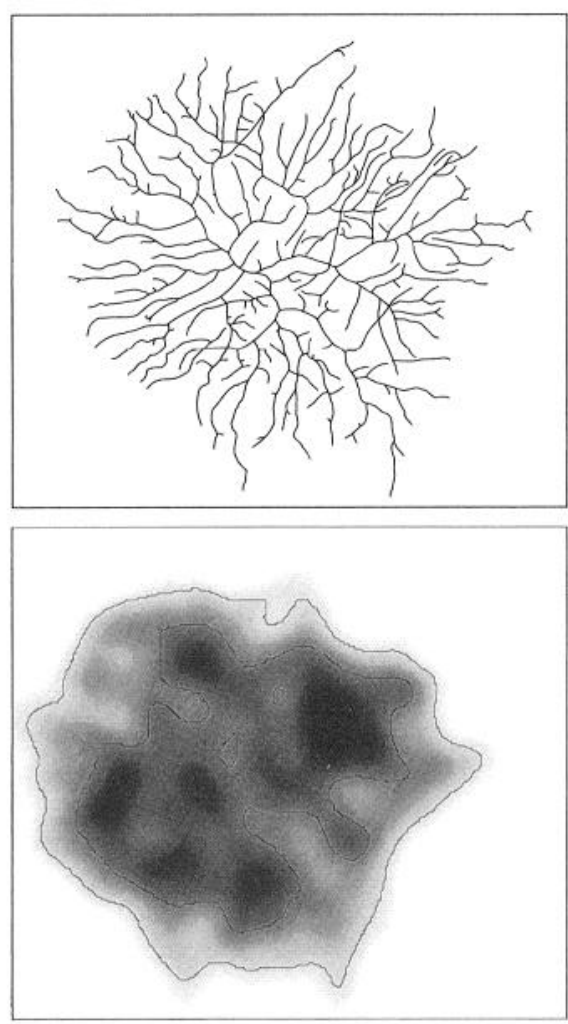

Figure 12. Method for quantifying the tendency of midget ganglion cells to form localized regions of high dendritic density within their dendritic fields. $A$, Camera lucida tracings of a midget cell from the nasal retinal periphery (left) and a parasol cell (the other common ganglion cell type of the primate retina) also from the retinal periphery (right). To facilitate comparison of branching patterns, the two cell types are shown at different magnifications. $B$, Simplified tracing of the dendritic branching pattern of both cells (soma and axon omitted). The midget cell dendritic tree shows multiple regions of high and low dendritic densities; by contrast, the parasol cell shows a comparatively even, space-filling branching pattern. $C$, Contour plots made from digitized and smoothed images of dendritic tree outlines shown in $B$. Contour lines follow the $30 \%$ and $70 \%$ of maximum density values. For the midget cell this defines distinct regions of high and low dendritic density. The regions bounded by the $70 \%$ contour lines are designated as dendritic clusters. For the parasol cell, dendritic density is lower in the periphery of the field and relatively uniform over the center of the field; no patches of high and low density, as defined by the $30 \%$ and $70 \%$ contour lines, can be seen.
Several features of the morphology of the cells indicated that within each patch, all the members of a single mosaic had been injected. First, the arrangement of the cell bodies, evaluated by measuring cell-to-cell spacing, was highly regular. Second, the coverage factor was constant across a patch, and was the same for patches from different retinal eccentricities. Third, the depth of stratification of all injected cells in a patch was identical. Fourth, adjacent dendritic trees were shaped to interdigitate and fill the available space like interlocking pieces of a jigsaw puzzle (Wässle et al., 1981c). Finally, when a cell was not completely filled, an obvious hole in the mosaic was apparent.

The largest patch, containing 42 inner midget cells, illustrates the regular intercell spacing and uniform coverage for this mosaic (Fig. 15). For all neighboring cells the dendritic field coverage was consistently less than, but very close to 1 . That is, the adjacent dendritic trees approached one another but showed virtually no overlap. Moreover, single dendrites from neighboring cells rarely crossed over one another and in no case did the dendritic trees intermingle. Multiplying the density of cells in this patch $\left(40\right.$ cells $\left./ \mathrm{mm}^{2}\right)$ by the mean dendritic field area $\left(0.027 \mathrm{~mm}^{2}\right)$ gave a coverage of 1.1 . This calculated coverage suggested that there should be a some small overlap of the dendritic trees. However, as shown in Figure $15 C$, the irregular, interlocking shape of the dendritic trees served to reduce the real coverage to 1 , or slightly less than 1 . The regular spacing of the cell bodies in the patch is shown in Figure $15 \mathrm{~B}$. One measure of this regularity is given by the ratio of the mean nearest neighbor distance to its standard deviation (Wässle and Riemann, 1978). For the patch of peripheral inner midget cells shown in Figure 15, the mean nearest neighbor distance was $145 \mu \mathrm{m}$ and the standard deviation was $18 \mu \mathrm{m}$, giving a ratio of 8 , which approaches the high degree of regularity $(\sim 9.5)$ found for the peripheral red/green cone mosaic (Curcio et al., 1991).

Comparison of neighboring inner and outer patches in a single retina confirmed that the outer midget cells were consistently about 30\% smaller in dendritic field diameter than their inner counterparts (Fig. 16). Both the inner and outer mosaics had a coverage very close to 1 . As a consequence, the outer cells formed a mosaic of higher density than the inner cells. The density ratio of outer to inner midget cells was 1.7:1. Thus, at least beyond 


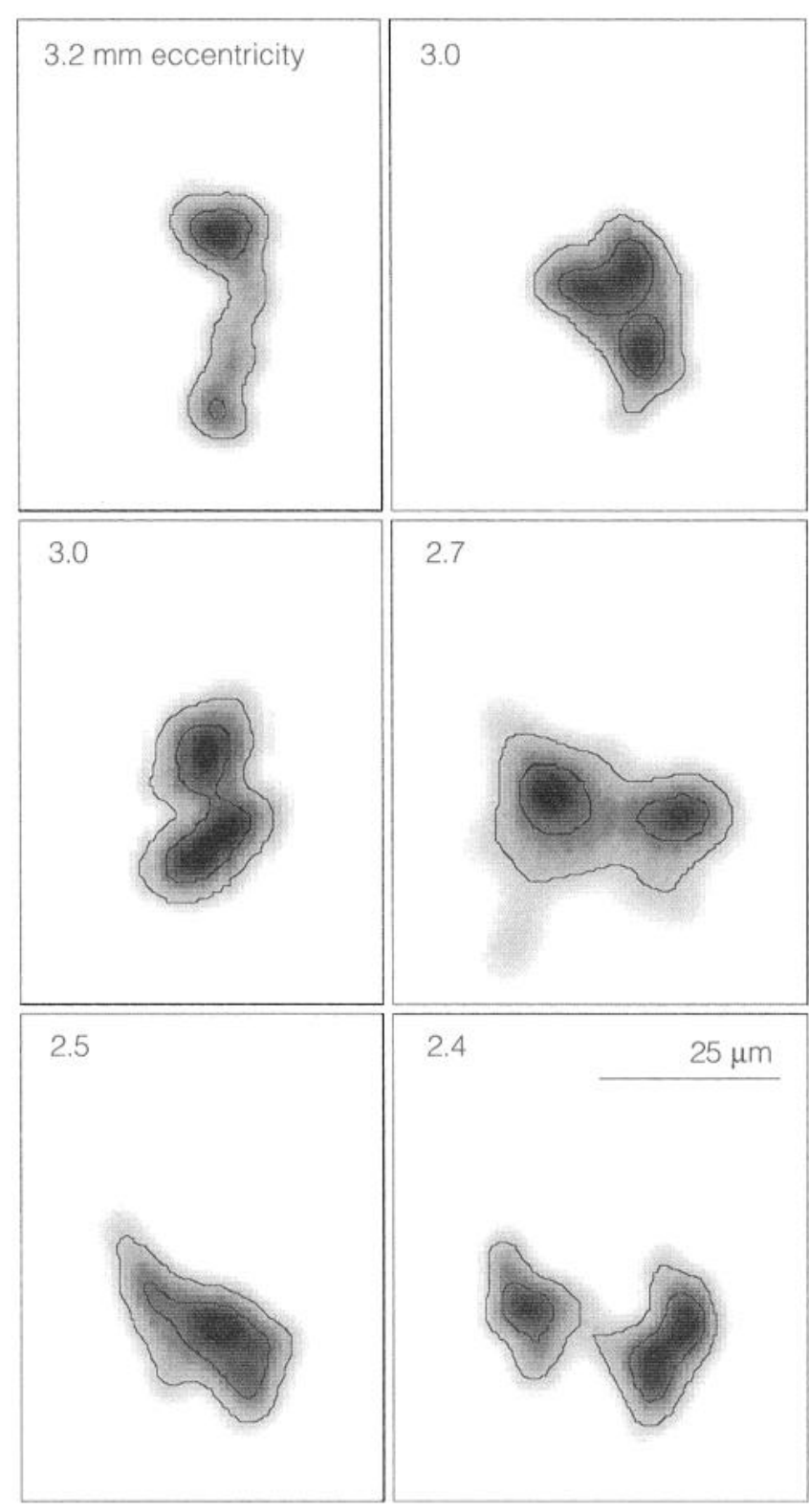

Figure 13. Dendritic clustering in midget cells is first observed between 2.4 and $3.2 \mathrm{~mm}$ eccentricity. Smoothed gray scale images and contour plots of midget cells from the near peripheral retina are shown. Contour lines follow the $30 \%$ and $70 \%$ density values as in Figure 12 . At this eccentricity the cells show a distinct tendency to divide into two separate regions of high dendritic density. The dendritic clusters may be relatively widely spaced as for the cells shown at $3.2,2.7$, and $2.4 \mathrm{~mm}$ eccentricity, or they may be closely spaced as for the two cells shown at $3.0 \mathrm{~mm}$. Only one cell in the sample of filled cells over this eccentricity range (lower left, $2.5 \mathrm{~mm}$; camera lucida tracing for this cell is shown in the upper left of Fig. 6) had an arbor that did not divide into clusters.

$7 \mathrm{~mm}$ eccentricity, there must be five outer midget cells for every three inner midget cells. The data on inner and outer dendritic field size for eccentricities less than $7 \mathrm{~mm}$ (Fig. 10) suggested that this density difference may also hold at more central locations.

The range of dendritic field sizes observed within a single patch, whether of inner or outer cells, can also account for the large local scatter in dendritic field diameter illustrated in Figure 4. For example, the inner cells in the patch shown in Figure 15 ranged in diameter from 140 to $270 \mu \mathrm{m}(n=29$; mean $\pm \mathrm{SD}$
$=186 \pm 22 \mu \mathrm{m})$. Given that the ratio of inner to outer dendritic field diameter was $1.3: 1$, and assuming that the outer mosaic shows the same local scatter as the inner mosaic, a mean of $\sim 140 \mu \mathrm{m}$ and a diameter range of $\sim 100-200 \mu \mathrm{m}$ would be predicted for the outer midget cell mosaic at the retinal location shown in Figure 15. The predicted diameter range for all midget cells at this location would therefore be $\sim 100-270 \mu \mathrm{m}$. This variation of nearly threefold is close to that found for the midget sample as a whole and supports the hypothesis that the sample of midget cells shown in Figure 4 is derived from only two ganglion cell mosaics.

The detailed dendritic structure within the patches revealed the significant variation in the clustered dendritic morphology of the midget cells (Fig. 14). As in the total sample of midgets, the cells in the patches ranged from very densely branching and highly clustered, to sparsely branching and minimally clustered (e.g., arrowheads in Fig. 15 A indicate the two extremes). Thus, much if not all of the morphological variation that has been described for the sample of single cells can also be observed in any single small patch of cells.

The filled cell patches also revealed that the dendritic clusters and holes within the dendritic field of single midget cells were maintained in the cell mosaic as a whole (Figs. 17, 18). Based on the dendritic networks formed by other ganglion cell mosaics (e.g., Wässle et al., 1981a,b; Dacey, 1989), it was anticipated that the dendritic clusters and holes would interdigitate such that the dendritic network formed by the complete mosaic would display a uniform density. However, the midget cell dendritic trees did not overlap, and the holes were not filled in by the interdigitation of neighboring dendrites (Fig. 17). Contour plots of dendritic density across cell patches thus revealed the same regions of high and low density observed in single cells (Fig. 18).

\section{Discussion}

Midget ganglion cells: two types, two mosaics

In this study human midget ganglion cells were identified by their characteristic dendritic field size at a given retinal location. Midget cell dendritic fields showed no overlap in size with those of any other ganglion cell type at a given retinal location, and by this measure formed a singie distinct grouping. The human midgets were divided into two types, presumed to correspond to ON- and OFF-center cells, by the depth of stratification of their dendritic trees, in agreement with previous studies (Perry et al., 1984; Rodieck et al., 1985; Watanabe and Rodieck, 1989).

Despite the general agreement among previous studies, supported by the present results, regarding the subdivision of midget cells into only the inner and outer types, there is still some dispute about the number of ganglion cell types in the midget size range. A recent Golgi study of human retina has suggested that the ganglion cells with the smallest dendritic fields at all eccentricities can be subdivided by differences in dendritic field size alone (Kolb et al., 1992) into the Pl cells $(\sim 5-15 \mu \mathrm{m}$ diameter), and the P2 cells ( $\sim 10-60 \mu$ m diameter). In the present study no such subdivision on the basis of dendritic field diameter was possible (see Fig. 4). A distinct subgroup of midget cells in the far retinal periphery with dendritic field diameters in the range of $15-20 \mu \mathrm{m}$, as reported by Kolb et al. (1992), was not observed. The smallest peripheral midget cells had diameters of $35-45 \mu \mathrm{m}$ in the nasal retina; in the other retinal quadrants some cells as small as $50 \mu \mathrm{m}$ in diameter were found between 7 and $8 \mathrm{~mm}$ eccentricity (Fig. $4 A$ ). I can suggest two possible 

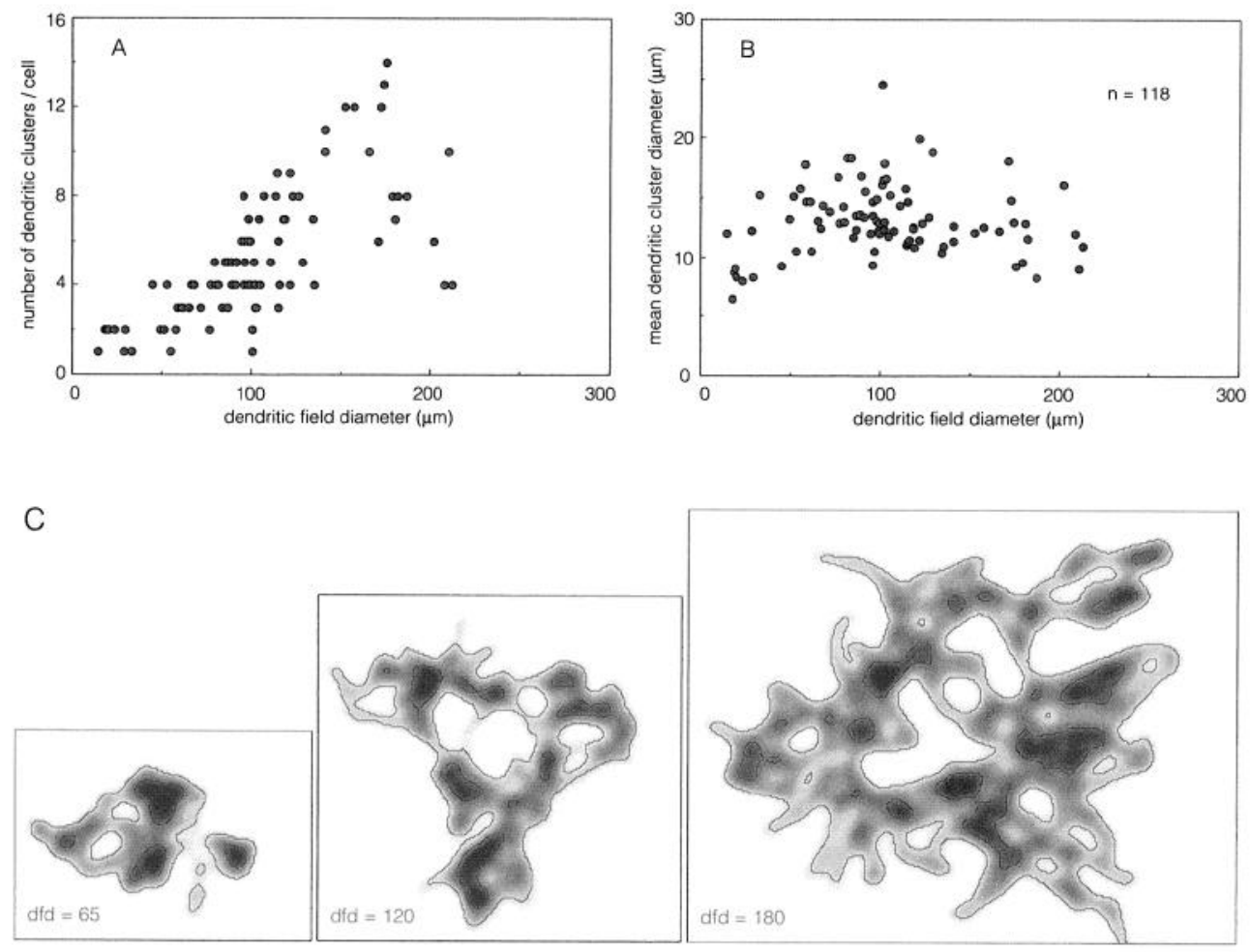

D

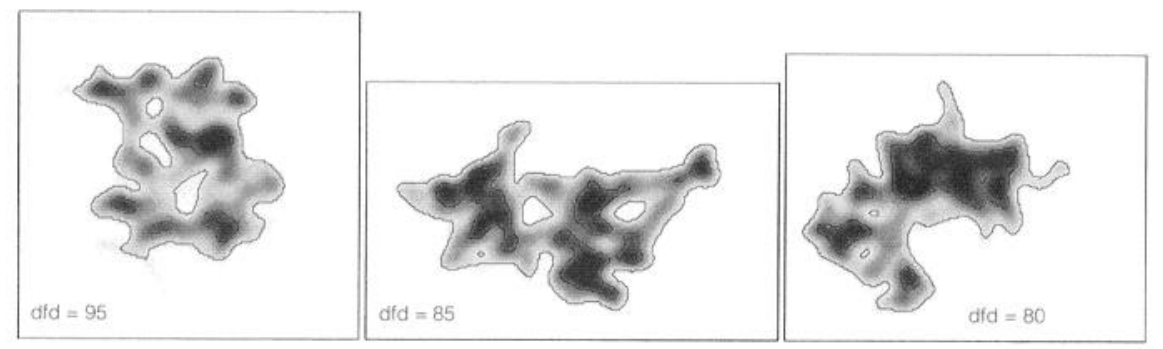

Figure 14. Number and size of midget cell dendritic clusters as a function of eccentricity. $A$, Number of dendritic clusters per cell plotted against dendritic field diameter. Average cluster number increases with increasing dendritic field size but cluster number is highly variable. $B$, Mean cluster diameter ranges between 10 and $20 \mu \mathrm{m}$ over most of the dendritic field size range. $C$, Contour plots of smoothed, gray scale images illustrate how the number of clusters increases with dendritic field size but the range of cluster sizes remains about the same. $D$, Contour plots illustrate the variability in cluster number for cells of similar dendritic field sizes. $d f d$, dendritic field diameter (in $\mu \mathrm{m}$ ). explanations for this discrepancy. Given the great variability in the dendritic field size range for the inner and outer midgets, such small cells in the retinal periphery could exist, especially in the smaller, outer cell mosaic, but they would be very rare and would not comprise a separate and complete mosaic (assuming a coverage of one or greater). Alternatively, the clustered nature of the peripheral midget cell's dendritic tree could be the basis for rare observations of peripheral midgets with small dendritic fields. Some cells possess multiple, spatially distinct arbors, each arbor much smaller than the total dendritic field (e.g., Figs. 9, 12); a partial Golgi impregnation of such a cell could result in an artifactual image of an extremely small dendritic field in the retinal periphery.

Although the existence of Kolb's P1 and P2 cell types could not be confirmed in the present study, the great variability in midget cell dendritic field size did suggest that distinct subpopulations beyond the inner and outer mosaics might exist in this sample. However, the range of dendritic field sizes within each mosaic argues against this possibility. The inner midget cells showed on average a $30 \%$ larger dendritic field diameter than their outer cell counterparts (Fig. 10); this difference is a property of the mosaic as a whole (Fig. 16). Taking both mosaics together, there is an almost threefold variation in dendritic field size at a given retinal location. This variation predicts nicely the degree of scatter shown in Figure 4 without recourse to additional unidentified cell types in this size range.

\section{Midget cell coverage and density}

Assuming that the coverage of 1 found for the midget cell patches holds over the entire retina, it is possible to calculate the density of midget cells using the dendritic field size data shown in Figure 4. Figure $19 \mathrm{~A}$ plots midget ganglion cell density (coverage/dendritic field area in cells $/ \mathrm{mm}^{2}$ ) as a function of retinal eccentricity using the values from the curve fit to the data in Figure 4 . These values were compared with the mean density values from the temporal, upper and lower meridians for the total ganglion cell counts in human retinas given by Curcio and Allen (1990). This comparison suggests that the proportion of midget cells steadily increases as the fovea is approached. Density was relatively constant at about $45-50 \%$ of the total ganglion cell population from 15 to $9 \mathrm{~mm}$ eccentricity; from 8 to $3 \mathrm{~mm}$ eccentricity, density increased to about $95 \%$ of the total ganglion cell population (Fig. 19B).

This picture of human midget ganglion cell topography contrasts with results in macaque, where midget ganglion cells have been reported to make up a constant proportion of the ganglion cell population, about $80 \%$, at all retinal locations (Perry et al., $1984)$, so it is necessary to consider possible sources of error in 

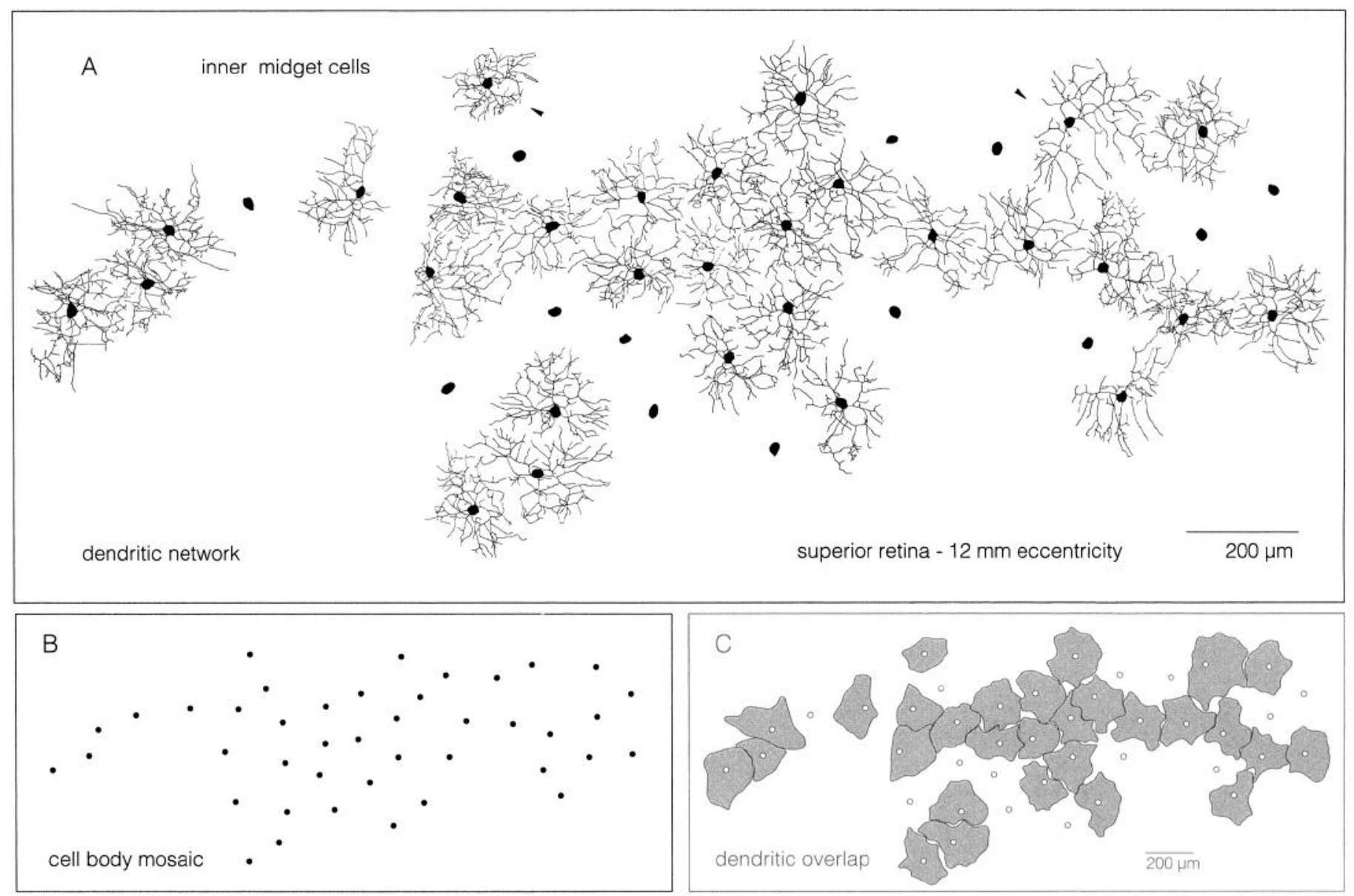

Figure 15. The midget cell mosaic. $A$, Patch of 42 inner midget cells intracellularly filled with Neurobiotin. Tracings of the dendritic trees were made for all cells ( 29 cells) that showed complete dendritic filling. $B$, Injected cell bodies (solid circles) show a highly regular distribution. $C$, Tracings around the dendritic fields of filled cells reveal that neighboring dendritic trees do not overlap and show a coverage of 1 or slightly less.

the results plotted in Figure 19. The coverage of 1 for the midget cells is derived from cell patches at eccentricities of $7 \mathrm{~mm}$ or greater. If midget coverage progressively decreased toward the fovea, the percentage of midget cells would be lower. This seems highly unlikely, however, because it would mean that the midget cells would not have the minimum coverage required to sample all points in the visual field. Alternatively, there is the possibility that Curcio and Allen (1990) overestimated the total number
Figure 16. Difference in size and density of inner and outer midget cell mosaics. Cell bodies are shown in darker shading and the dendritic fields are outlined and lightly shaded. Adjacent patches of inner and outer midget cells show that both cell types show similar coverage very close to 1 . Outer cells have on average smaller dendritic field diameters, resulting in a mosaic of higher density. Ratio of outer cell density to inner cell density is $1.7: 1$

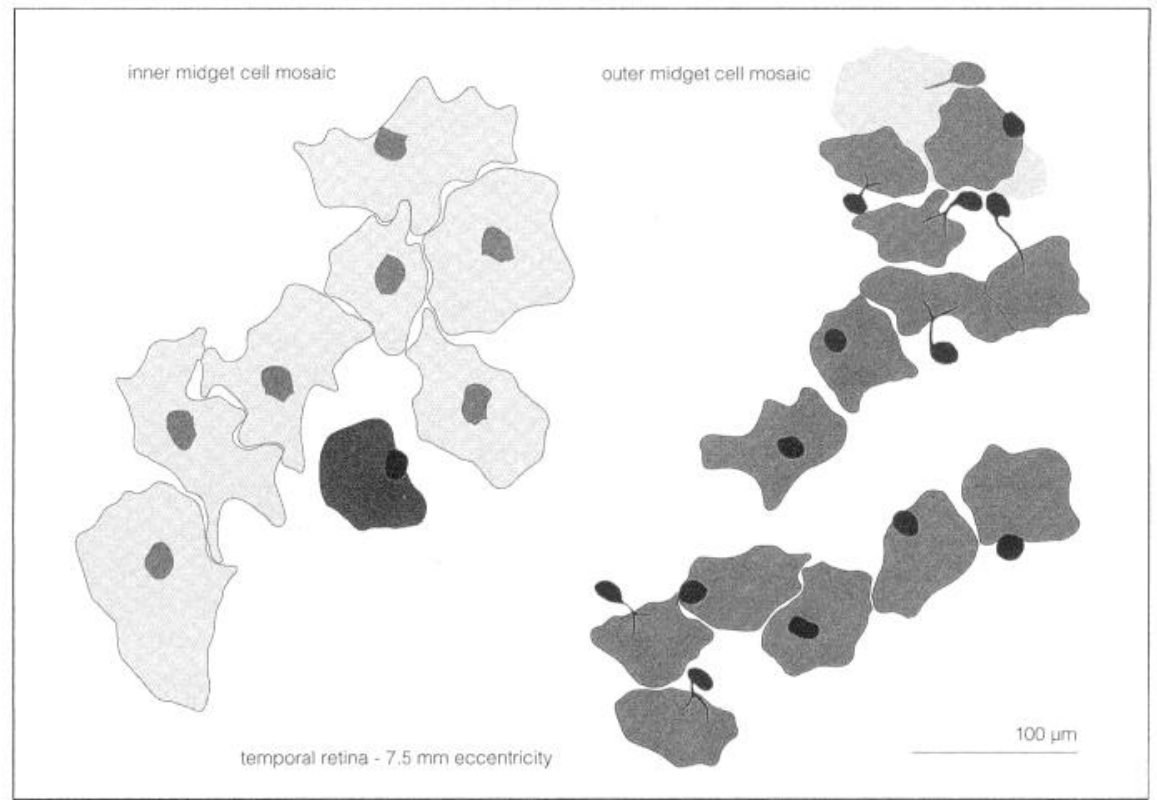




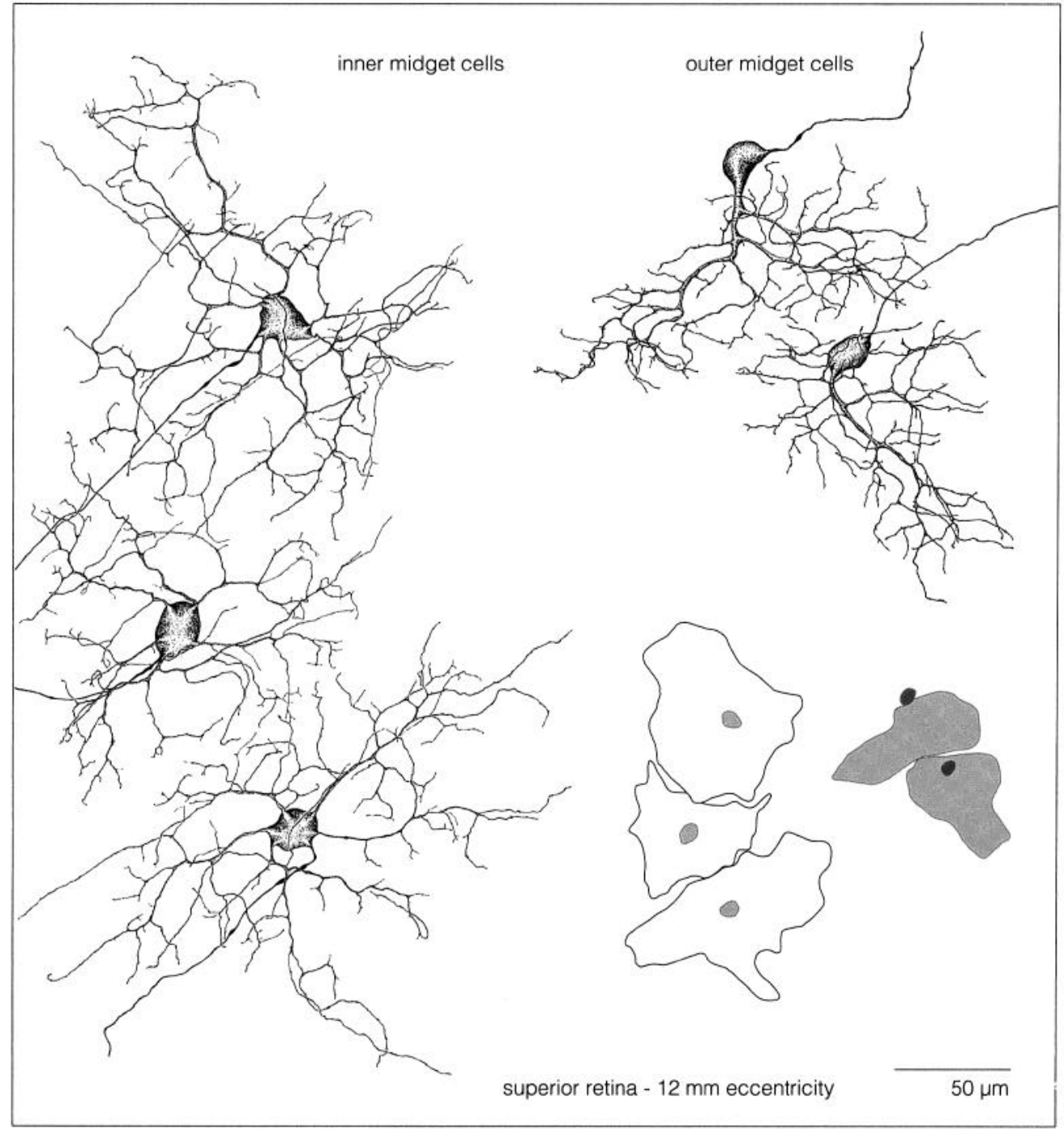

Figure 17. Neighboring midget cell dendritic trees avoid intersecting and maintain a constant coverage. Highmagnification camera lucida tracings of inner and outer midget cell patches show that the individual dendrites of neighboring dendritic trees avoid entering into adjacent fields. The result is that the spatial inhomogeneities of the individual dendritic trees are preserved within the cell patch. Outlines of the dendritic trees (inset at lower right) illustrate the lack of overlap of the neighboring dendrites. of ganglion cells in the retinal periphery, and that midget cells actually comprise a much greater proportion than the $45-50 \%$ shown in Figure 19. The number of amacrine cells present in the ganglion cell layer increases greatly in the retinal periphery, and if some of the displaced amacrines were counted as ganglion cells, ganglion cell density would be significantly overestimated. In the macaque retina, immunostaining for GABA combined with retrograde degeneration of ganglion cells has shown that in the far periphery about $80 \%$ of the neurons in the ganglion cell layer were displaced amacrine cells (Wässle et al., 1990). In the human retina, Curcio and Allen (1990) estimated the number of displaced amacrine cells based on soma size and other morphological criteria to reach about $75 \%$ in the far retinal periphery in fair agreement with the more conclusive findings in macaque. Thus, it seems unlikely that the human ganglion cell counts are in error by more than $5 \%$.

The central-to-peripheral decrease in the proportion of midget cells supports the previous suggestion that the ratio of human midget to parasol ganglion cells changes from about $30: 1$ in the central retina to about $3: 1$ in the retinal periphery (Dacey and Petersen, 1992). It has been reported that the ratio of the densities of parvocellular to magnocellular neurons in the macaque dorsal lateral geniculate also changes from about $4: 1$ in the far periphery to about 40:1 in the central representation (Connolly and Van Essen, 1984). The present data on midget cell density thus provide renewed support for the hypothesis that the different threshold gradients observed for the sustained-chromatic and transient-luminance channels of human vision are related to the different density gradients of the magno-and parvocellular pathways (Drasdo et al., 1991; for review, see Drasdo 1991).

\section{Midget cell Nyquist frequency and visual acuity}

It is now well accepted that for central vision, spatial acuity is limited by the spacing of the cone photoreceptors (Banks et al., 1987; Williams and Coletta, 1987; Hirsch and Curcio, 1989; Anderson et al., 1991). However, beyond about $6-7^{\circ}$ eccentricity, the maximum spatial resolution afforded by cone spacingthe Nyquist frequency-exceeds psychophysical measures of visual acuity. The cone Nyquist frequency falls off to about 10 cycles/degree peripherally, whereas visual acuity declines sharply to less than 1 cycle/degree in the peripheral temporal retina.

Two psychophysical studies have suggested that the density of parvocellular-projecting ganglion cells may limit spatial resolution in the periphery (Thibos et al., 1987; Merigan and Katz, 1990). In these studies measures of grating acuity were compared with Nyquist frequencies calculated from published values of 
Figure 18. Contour plots of dendritic density show that inhomogeneities exist within the midget cell mosaic as a whole. Holes in individual dendritic trees are not filled in by neighboring trees. A:Left, Tracings around the five individual inner midget cell dendritic trees that make up a patch show no overlapping dendrites. Right, Contour plot of $30 \%$ and $70 \%$ of maximum density of the smoothed gray scale image of the patch. Retinal eccentricity $=13$ $\mathrm{mm}$. B:Left, Tracings around four individual dendritic trees that make up a more centrally located patch of inner midget cells. Right, Contour plot as in $A$. Retinal eccentricity $=9 \mathrm{~mm}$.
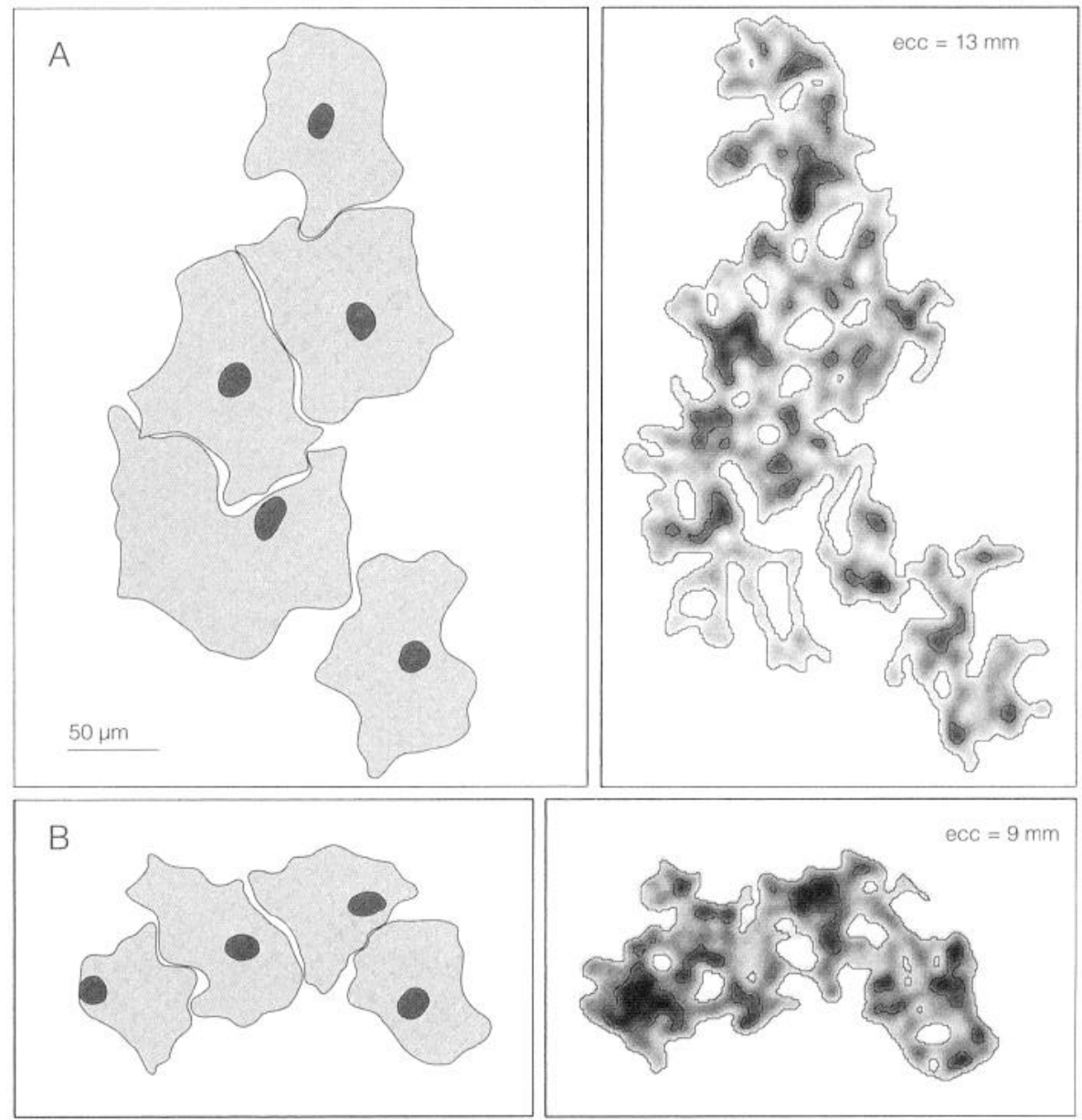

midget cell density across the macaque retina. Merigan and Katz compared grating acuity in macaque monkey with the Nyquist frequency derived from the estimated density of a single midget cell mosaic, that is, one-half the estimated total midget cell density, assuming that a single mosaic represents an independent sampling array. Thibos and colleagues compared human grating acuity, using interference fringes imaged directly on the retina, to estimates of total midget cell density in macaque monkey. Despite the twofold variation in ganglion cell density that was employed, both studies suggested that midget cell density sets the acuity limit beyond about $10^{\circ}$, and this conclusion has gained some acceptance (Lennie et al., 1990; Wässle and Boycott, 1991).

There are two potential difficulties with the above results that have prompted another look at the relationship between the midget cell mosaic and spatial acuity. First, the calculations in both studies were based on ganglion cell density estimates in which midget cells were assumed to make up a constant proportion of the retinal ganglion cells across the retina (Perry et al., 1984). Thus, their cell density estimates for the macaque differed from those calculated here for the human. Second, a more recent study (Anderson et al., 1991) has found significantly lower values for human spatial resolution across the visual field than those measured by Merigan and Katz or Thibos and colleagues. Both Merigan and Katz and Thibos and colleagues measured grating acuity using a discrimination protocol in which the orientation of the grating was detected. Anderson and col- leagues suggest that such an orientation protocol is not "aliasfree" and can lead to acuity estimates that are up to 1.5 times higher than the Nyquist frequency of the underlying mosaic (Williams and Coletta, 1987). These authors therefore adopted a discrimination protocol based on the detection of the direction of motion of a grating, which they argued was free of sampling artifacts. Anderson and colleagues then went on to compare their results with the Nyquist frequency calculated from measures of total ganglion cell density in the human retina by Curcio and Allen (1990). Not surprisingly, they found that the Nyquist frequency for the total ganglion cell population was higher, by a factor of $\sim 2$, than achromatic acuity.

The finding of a coverage of 1 for the human midget ganglion cells makes it now possible to calculate the highest anatomical resolving power for the midget cell mosaic. The Nyquist frequency, assuming hexagonal packing of ganglion cells, equals $1 / \sqrt{ } 3(D)$, where $D$ is the intercell spacing in degrees (Snyder and Miller, 1977). For the midget cells, $D$ is equivalent to the dendritic field diameter. Figure $20 \mathrm{~A}$ plots spatial resolution in cycles/degree for the midget ganglion cells from $1^{\circ}$ to $55^{\circ}$ using the dendritic field diameters given by the equation for the curve fit to the data in Figure 4. These data are compared to the recent data of Anderson et al. (1991), Merigan and Katz (1990), and Thibos et al. (1987) and the classical findings of Wertheim (1891). In the retinal periphery the grating acuities measured by Thibos and colleagues in human and by Merigan and Katz in macaque are about 1.5-2 times higher than the human midget cell Nyquist 

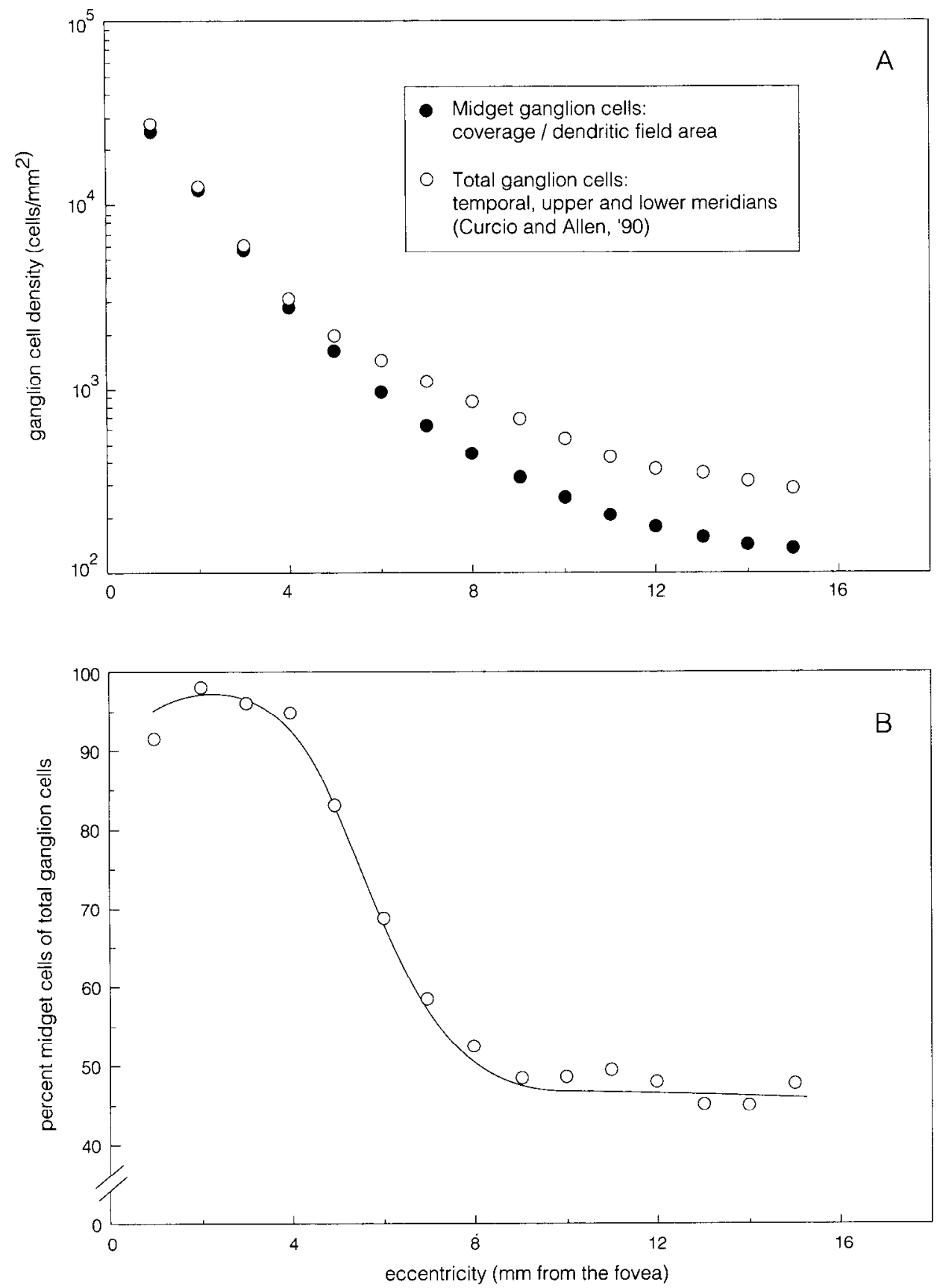

Figure 19. Calculation of midget ganglion cell density as a function of retinal eccentricity. $A$, Midget cell density is calculated from the dendritic field area given by the equation for the curve shown in Figure 4 and a coverage of 1 across the retina. The midget cell densities are compared with published values for total ganglion cell density (Curcio and Allen, 1990). Total ganglion cell density was taken as the mean of values for the temporal, upper and lower meridians. $B$, From the two sets of data plotted in $A$ the percentage of midget cells of the total ganglion cell population is shown as a function of eccentricity. From 15 to $8 \mathrm{~mm}$ eccentricity, the midget cells make up $45-50 \%$ of the ganglion cells. From 8 to $4 \mathrm{~mm}$, relative density increases dramatically to reach about $95 \%$ of the total ganglion cells. frequency. By contrast, the data given by Anderson et al. (1991) for achromatic acuity closely match the midget Nyquist frequency from $55^{\circ}$ to about $6-7^{\circ}$. In addition, the classical data of Wertheim, considered an underestimate of peripheral acuity by modern standards, also closely match both the anatomical data and the results of Anderson and colleagues from about $10^{\circ}$ to the far periphery. The correspondence between these diverse sets of data supports the conclusion that spatial resolution measured by Anderson and colleagues is a function of the sampling density of the mosaic of midget cell dendritic fields. The previously reported correspondence between human and macaque acuity and macaque midget cell density may be a consequence of overestimates of both acuity and midget cell density in the retinal periphery.

Further evidence that the midget cell mosaic limits acuity in the retinal periphery relates to the transition in dendritic morphology seen for midget cells around $6^{\circ}$ eccentricity. This is the eccentricity where visual acuity begins to match the midget cell Nyquist limit. Figure $20 B$ indicates that between $0^{\circ}$ and $6^{\circ}$, all midget ganglion cells show the minimum dendritic tree diameters, $5-10 \mu \mathrm{m}$. At this eccentricity the ratio of ganglion cells to cones is greater than 2:1 (Wässle et al., 1989a; Curcio and Allen, 1990). There are therefore enough ganglion cells that signals from a single cone photoreceptor can be conveyed independently to both ON- and OFF-center midget ganglion cells. Consequently, the spatial resolution afforded by cone spacing can be preserved in the output of both the ON and OFF midget ganglion cell mosaics. Beyond $6^{\circ}$ eccentricity, midget cell dendritic trees enlarge and form multiple dendritic clusters. These clusters suggest the convergence of input from more than one 
Figure 20. Comparison of the midget cell Nyquist frequency with measurements of human spatial resolution. $A$, Given a constant dendritic field overlap of 1 , the midget dendritic field diameter is equivalent to intercell spacing and, assuming approximately hexagonal packing, the Nyquist limit for human midget cells $=1 /(\mathrm{V} 3 \times$ dendritic field diameter). To generate the curve shown in this figure for the midget cells, dendritic field diameter was taken from the equation for the curve fit to the data given in Figure 4. The curves for the midget cells and the data of Anderson et al. (1991) are closely matched from $55^{\circ}$ to about $6^{\circ}$ eccentricity. The curve shown for Wertheim's classical data also matches the midget Nyquist frequency, as well as the data of Anderson and colleagues, from about $10^{\circ}$ out to the far periphery. (Wertheim's data were given as normalized relative to foveal resolution, his Table 2; absolute resolution in cycles/degree was calculated for the temporal retina by reference to the data provided in Table 1 of the original work). Other recent measures of grating acuity in both human and macaque (Thibos et al., 1987; Merigan and Katz, 1990) give higher values for spatial resolution in the periphery. $B$, Scatterplot of dendritic field diameter versus eccentricity for midget cells in the central and near peripheral retina provides an anatomical explanation for the point at which the Nyquist frequency given by midget cell dendritic field diameter matched spatial acuity. From 0 to $6^{\circ}$ midget cells have single arbors that receive signals from only a single cone photorcceptor; in this region conc spacing limits spatial resolution. Beyond $6^{\circ}$ the midget cells show multiple dendritic clusters that are assumed to receive convergent input from a number of cones and the acuity limit would thereby be shifted to the midget cells at this eccentricity. Open circles, temporal, upper and lower retina; solid circles, nasal retina.
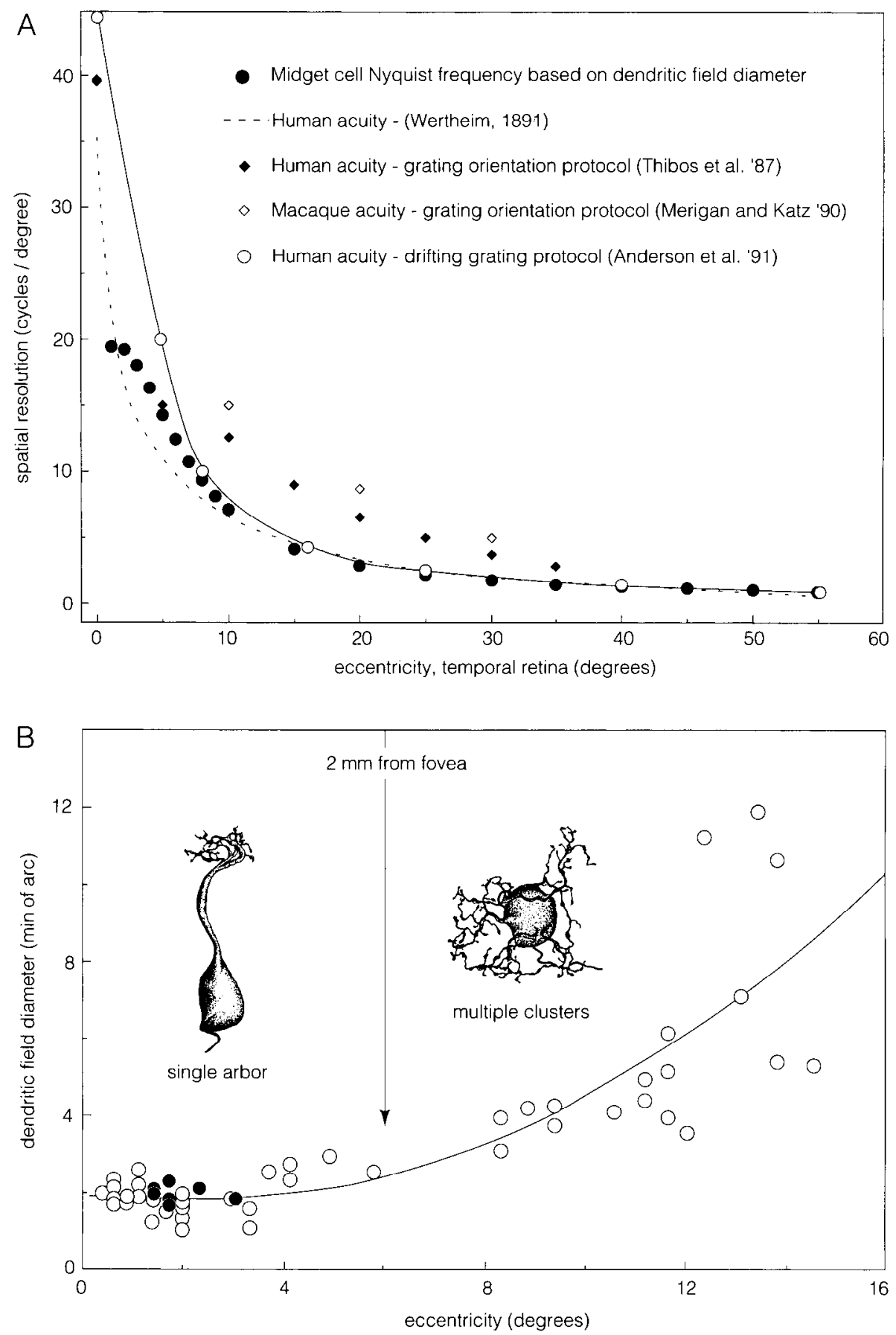

cone bipolar cell. Consistent with this conclusion, it has been shown that at about this eccentricity the ratio of ganglion cells to cones declines to less than $2: 1$, so convergent input from multiple cones to single midget ganglion cells becomes probable (Wässle et al., 1990). Correspondingly, spatial acuity should no longer attain the cone Nyquist frequency but instead must be limited by the midget cell Nyquist frequency.

\section{An asymmetry in the spatial scale of the $O N$ and $O F F$ midget} mosaic

In a previous report we showed that the inner midget and parasol ganglion cells (presumed ON-center) were consistently larger in diametcr than their outer (presumed OFF-center) counterparts
(Dacey and Petersen, 1992). Such an asymmetry has not been previously noted for either macaque or human ganglion cells, though the presence of size differences between ON- and OFFcenter ganglion cell pairs has been observed in other mammalian species (for review, see Peichl, 1991). This finding was confirmed and extended in the present study. Intracellular staining of midget cell patches showed that the dendritic coverage for both the inner and outer cell mosaic was the same. As a consequence, the smaller-diameter outer cells formed a higher-density mosaic than the larger-diameter inner cells. Given a difference of about $30 \%$ in dendritic field diameter, the density ratio of outer to inner midget cells should be about 1.7:1. This result also predicts that the spatial resolution afforded by the OFF-center mosaic 

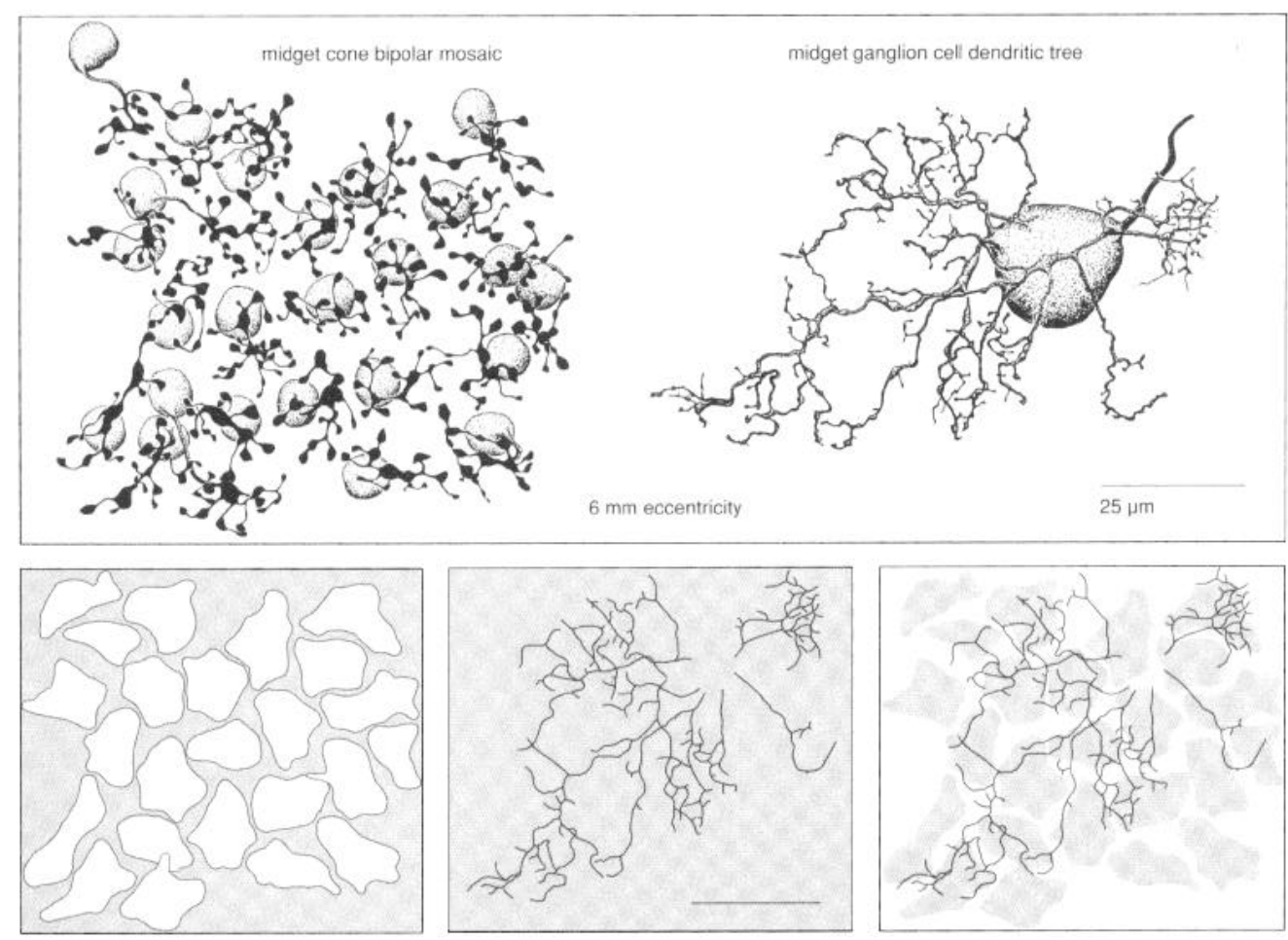

Figure 21. Hypothesis that dendritic clustering in peripheral midget cells reflects selective connections with a subset of midget bipolar cells. The upper panel shows a camera lucida tracing of a small patch of presumed flat midget cone bipolar cells from macaque monkey retina revealed by immunostaining for the calcium-binding protein recoverin (Milam et al., 1993). The cell bodies are stippled and the axon terminals are solid. Also shown is a tracing of a human midget ganglion cell at about the same retinal eccentricity. In the lower left panel a tracing has been made around the axon terminal arbors of all bipolar cells to illustrate their mosaic organization in the IPL. The middle panel is a simplified tracing of the dendritic branches of the midget ganglion cell to illustrate more clearly the tendency of the dendrites to form clusters. Scale bar, $25 \mu \mathrm{m}$. In the right panel the ganglion cell tree has been superimposed upon the bipolar mosaic. The dendritic tree is not arranged to make uniform contact with all of the 17 or so bipolar terminals within its field. The size of the dendritic clusters approximates the size of one to three bipolar axon terminal fields. The holes between the clusters are regions where bipolar terminals may make few if any contacts with the midget cell dendritic tree. should be about 1.3 times that of the ON-center mosaic, at least in the retinal periphery where such a size difference has been directly observed. There is psychophysical evidence that the visual system shows a greater sensitivity to decrements in light level than to light increments (e.g., Bowen et al., 1989; Tyler et al., 1992; for review, see Fiorentini et al., 1990; Bowen et al., 1992), but how this finding relates to receptive field sizes of $\mathrm{ON}$ - and OFF-center neurons is not clear. Human visual evoked potentials generated by positive and negative contrast stimuli believed to isolate the ON- or OFF-visual pathways suggest that the response to stimulation of the OFF-pathway shows finer spatial tuning than the ON-pathway response (Zemon et al., 1988), but this conclusion has not yet been supported by other approaches.

\section{Dendritic clusters and the color selectivity hypothesis}

Beyond the central retina, midget cells possess dendritic trees that are not spatially homogeneous; terminal dendrites cluster into small regions of high density. Moreover, because the dendritic trees of neighboring midget cells do not overlap, the clustered dendritic morphology is preserved in the overall midget cell mosaic. Previous studies of midget cell morphology have not commented on the tendency for dendritic clustering, but a careful review of the published camera lucida tracings reveals many examples of this type of morphology (Perry et al., 1984, their Fig. $2 C-F$; Watanabe and Rodieck, 1989, their Fig. $2 d-f$; Kolb et al., 1992, their Fig. 18), and Kolb and colleagues did note that in mid-peripheral retina midget cells sometimes "have two dendritic heads." The present results show that the tendency for the midget cell to form spatially distinct dendritic clusters is a characteristic feature of the great majority, if not all, of the midget cells beyond the central 2-3 $\mathrm{mm}$.
In central retina the cone-specific center responses of parvocellular-projecting ganglion cells are presumed to be a consequence of the one-to-one connectivity between a single cone, a midget bipolar cell, and a midget ganglion cell (Boycott and Dowling, 1969; Kolb, 1970; Kolb and Dekorver, 1991; Calkins et al., 1992). However, color-opponent responses have also been observed beyond the central 6-7 ${ }^{\circ}$ (Wiesel and Hubel, 1966; Gouras, 1968; DeMonasterio and Gouras, 1975), where it is probable that midget ganglion cells receive convergent input from more than one midget bipolar cell. At this eccentricity it is not at all clear how a cone-specific center response would be generated. In a recent review, Wässle and Boycott (1991) speculated that color-opponent receptive fields may arise by selective connections between midget bipolar cells and ganglion cells in the IPL. They pointed out that, in peripheral retina, irregularity in the dendritic morphology of the midget cells may reflect this selectivity to some degree. This idea is a logical extension of recent findings indicating that horizontal cells do not make color-selective connections with cones (Boycott et al., 1987; Wässle et al., 1989a; Dacheux and Raviola, 1990), but that midget bipolar cells contact only single cones well out into the retinal periphery (Boycott and Wässle, 1991). It has now been shown that the density of cone bipolar cells is great enough to deliver cone-specific signals to the IPL, even in the periphery, where the ratio of cone bipolar cells to cones allows for one ON and one OFF midget bipolar cell per cone (Martin and Grünert, 1992; Milam et al., 1993). Moreover, recent electrophysiological results suggest that both the centers and surrounds of coloropponent cells receive specific red cone or green cone input (Reid and Shapley, 1992), further reinforcing the requirement for color-selective connections at the level of the midget cone bipolarmidget ganglion cell connection. 
Is it possible that the dendritic clusters reflect selective connections made with a cone-specific subset of bipolar cells within the midget cell's dendritic field? In thinking about this question it is helpful to compare the midget cell dendritic morphology with that of the mammalian horizontal cell. The main dendrites of horizontal cells give rise to multiple small clusters of fingerlike terminals; each terminal marks a region of synaptic contact with a single cone pedicle. Because the horizontal cell makes nonselective contact with every pedicle in its field, the dendritic clusters provide an unambiguous map of the spacing and density of the array of overlying cone pedicles. The dendritic clusters of the midget ganglion cells are not as distinctly defined as those of the horizontal cells but could be clearly delineated by making topographic maps of dendritic density. Isodensity maps showed the midget cells to have highly clustered dendritic trees when compared to the parasol ganglion cell type. For the horizontal cell dendritic clusters it is only the visualization of the overlying cone pedicles that clearly reveals their functional significance. Similarly, superposition of the mosaic of midget cone bipolar axon terminals and the midget ganglion cell dendritic tree might demonstrate whether the dendritic clustering reflects selective connections between the two mosaics.

Recently a selective immunostain for the presumed flat midget bipolar cells in macaque retina (Milam et al., 1993) has made such an exercise possible. Figure 21 compares the bipolar axon terminal mosaic to the dendritic morphology of a single human midget cell at $6 \mathrm{~mm}$ eccentricity. Overlaying the midget cell dendritic field with the mosaic of bipolar axon terminals reveals two important features of their spatial relationship. First, the sizes of the midget cell dendritic clusters are appropriate to make selective contact with one or a few bipolar axon terminals in the field. Second, the "holes" in the dendritic field that separate the clusters suggest that a number of bipolar terminals in the midget cell's field would not make direct contact with the midget cell dendritic tree. In the example shown there are about 18 bipolar axon terminals in the midget cell's dendritic field, but only about nine of them significantly overlap the midget ganglion cell dendrites. It is possible, then, that a color-selective center response of the midget ganglion cell derives from a submosaic of midget bipolar cells that convey signals from only one population of cones, either red or green. If this were the case, then the bipolar cells that overlap with the "holes" in the midget cells dendritic field could mediate the opponent surround by providing indirect inhibitory input via a sign-inverting amacrine cell. This anatomical picture is also consistent with the evidence that for many red-green opponent cells the "surround" does not in fact surround the center but is coextensive with it (Reid and Shapley, 1992).

\section{References}

Anderson SJ, Mullen KT, Hess RF (1991) Human peripheral spatial resolution for achromatic and chromatic stimuli: limits imposed by optical and retinal factors. J Physiol (Lond) 442:47-64.

Banks MS, Geisler WS, Bennett PJ (1987) The physical limits of grating visibility. Vision Res 27:1915-1924.

Bowen RW, Pokorny J, Smith V (1989) Sawtooth contrast sensitivity: decrements have the edge. Vision Res 29:1501-1509.

Bowen RW, Pokorny J, Smith VC, Fowler MA (1992) Sawtooth contrast sensitivity: effects of mean illuminance and low temporal frequencies. Vision Res 32:1239-1247.

Boycott BB, Dowling JE (1969) Organization of the primate retina: light microscopy. Philos Trans R Soc Lond [Biol] 255:109-184.

Boycott BB, Wässle H (1991) Morphological classification of bipolar cells of the primate retina. Eur J Neurosci 3:1069-1088.
Boycott BB, Hopkins JM, Sperling HG (1987) Cone connections of the horizontal cells of the rhesus monkey's retina. Proc R Soc Lond [Biol] 229:345-379.

Buhl EH, Peichl L (1986) Morphology of rabbit retinal ganglion cells projecting to the medial terminal nucleus of the accessory optic system. J Comp Neurol 253:163-174.

Calkins DJ, Schein SJ, Tsukamoto Y, Masarachia P, Sterling P (1992) Parallel pathways to midget ganglion cells in macaque fovea. Invest Ophthalmol Vis Sci 33:1173.

Connolly M, Van Essen D (1984) The representation of the visual field in parvicellular and magnocellular layers of the lateral geniculate nucleus in the macaque monkey. $\mathrm{J}$ Comp Neurol 226:544-564.

Creutzfeldt OD, Lee BB, Elepfandt A (1979) A quantitative study of chromatic organization and receptive fields of cells in the lateral geniculate body of the rhesus monkey. Exp Brain Res 35:527-545.

Curcio CA, Allen KA (1990) Topography of ganglion cells in human retina. J Comp Neurol 300:5-25.

Curcio CA, Allen KA, Sloan KR, Lerea CL, Hurley JB, Klock IB, Milam AH (1991) Distribution and morphology of human cone photoreceptors stained with anti-blue opsin. J Comp Neurol 312:610-624.

Dacey DM (1988) Dopamine-accumulating amacrine cells revealed by in vitro catecholamine-like fluorescence display a unique morphology. Science 240:1196-1198.

Dacey DM (1989a) Axon-bearing amacrine cells of the macaque monkey retina. J Comp Neurol 284:275-293.

Dacey DM (1989b) Monoamine-accumulating ganglion cell type of the cat's retina. J Comp Neurol 288:59-80.

Dacey DM (1990) The dopaminergic amacrine cell. J Comp Neurol 301:461-489.

Dacey DM (1993) Morphology of a small field bistratified ganglion cell type in the macaque and human retina. Vis Neurosci, in press.

Dacey DM, Petersen MR (1992) Dendritic field size and morphology of midget and parasol ganglion cells of the human retina. Proc Natl Acad Sci USA 89:9666-9670.

Dacheux RF, Raviola E (1990) Physiology of HI horizontal cells in the primate retina. Proc R Soc I ond [Biol] 239:213-230.

Dann JF, Buhl EH (1987) Retinal ganglion cells projecting to the accessory optic system in the rat. J Comp Neurol 262:141-158.

de Monasterio FM, Gouras P (1975) Functional properties of ganglion cells of the rhesus monkey retina. J Physiol (Lond) 251:116-195.

Derrington AM, Krauskopf J, Lennie P (1984) Chromatic mechanisms in lateral geniculate nucleus of macaque. J Physiol (Lond) 357:241265.

Drasdo N (1991) Neural substrates and threshold gradients of peripheral vision. In: Limits of vision (Kulikowski JJ, ed), Vol 5, Vision and visual dysfunction (Cronly Dillon JR, ed), pp 250-264. New York: Macmillan.

Drasdo N, Fowler CW (1974) Non-linear projection of the retinal image in a wide-angle schematic eye. Br J Ophthalmol 58:709-714.

Drasdo N, Thompson CM, Deeley RJ (1991) Psychophysical evidence of two gradients of neural sampling in peripheral vision. In: From pigments to perception (Valberg A, Lee BB, eds), pp 189-192. New York: Plcnum.

Famiglietti EV Jr, Kolb H (1976) Structural basis for ON- and OFFcenter responses in retinal ganglion cells. Science 194:193-195.

Fiorentini A, Baumgartner G, Magnussen S, Schiller PH, Thomas JP (1990) The perception of brightness and darkness: relations to neuronal receptive fields. In: Visual perception: the neurophysiological foundations (Spillmann L, Werner JS, eds), pp 129-161. San Diego: Academic.

Gouras P (1968) Identification of cone mechanisms in monkey ganglion cells. J Physiol (Lond) 199:533-547.

Heimer GV, Taylor CED (1974) Improved mountant for immunofluorescent preparations. J Clin Pathol 27:254-256.

Hirsch J, Curcio CA (1989) The spatial resolution capacity of human foveal retina. Vision Res 29:1095-1101.

Kaplan E, Lec BB, Shapcly RM (1990) New views of primate retinal function. In: Progress in retinal research, Vol 9 (Osborne N, Chader G, eds), pp 273-336. New York: Pergamon.

Kolb H (1970) Organization of the outer plexiform layer of the primate retina. Philos Trans $R$ Soc Lond [Biol] 258:261-283.

Kolb H, Dekorver L (1991) Midget ganglion cells of the parafovea of the human retina: a study by electron microscopy of serial sections. J Comp Neurol 303:617-636.

Kolb H, Linberg KA, Fisher SK (1992) Neurons of the human retina: a Golgi study. J Comp Neurol 318:147-187. 
Lennie P, D'Zmura M (1988) Mechanisms of color vision. CRC Crit Rev Neurobiol 3:333-400.

Lennie P, Trevarthen C, Van Essen D, Wässle H (1990) Parallel processing of visual information. In: Visual perception: the neurophysiological foundations (Spillmann L, Werner JS, eds), pp 103-128. San Diego: Academic.

Lennie P, Haake PW, Williams DR (1991) The construction of chromatically opponent receptive fields. In: Computational models of visual perception (Movshon JA, Landy SC, eds), pp 61-72. Cambridge, MA: MIT Press.

Leventhal AG, Rodieck RW, Dreher B (1981) Retinal ganglion cell classes in the old world monkey: morphology and central projections. Science 213:1139-1142.

Lynch JJ, Silveira LCL, Perry VH, Merigan WH (1992) Visual effects of damage to $P$ ganglion cells in macaques. Vis Neurosci 8:575-583.

Martin PR, Grünert U (1992) Spatial density and immunoreactivity of bipolar cells in the macaque monkey retina. J Comp Neurol 323: 269-287.

Merigan WH (1989) Chromatic and achromatic vision of macaques: role of the $P$ pathway. $J$ Neurosci 9:776-783.

Merigan WH, Eskin TA (1986) Spatio-temporal vision of macaques with severe loss of $P \beta$ retinal ganglion cells. Vision Res 26:17511761.

Merigan WH, Katz LM (1990) Spatial resolution across the macaque retina. Vision Res 30:985-991.

Merigan WH, Katz LM, Maunsell JHR (1991) The effects of parvocellular lateral geniculate lesions on the acuity and contrast sensitivity of macaque monkeys. J Neurosci 11:994-1001.

Milam AH, Dacey DM, Dizhoor AM (1993) Recoverin immunoreactivity in mammalian cone bipolar cells. Vis Neurosci 10:1-12.

Peichl L (1991) Alpha ganglion cells in mammalian retinae: common properties, species differences, and some comments on other ganglion cells. Vis Neurosci 7:155-169.

Perry VH, Cowey A (1988) The lengths of the fibres of Henle in the retina of macaque monkeys: implications for vision. Neuroscience 25:225-236.

Perry VH, Oehler R, Cowey A (1984) Retinal ganglion celis that project to the dorsal lateral geniculate nucleus in the macaque monkey. Neuroscience 12:1101-1123.

Polyak SL (1941) The retina. Chicago: University of Chicago.

Reid RC, Shapley RM (1992) Spatial structure of cone inputs to receptive fields in primate lateral geniculate nucleus. Nature 356:716718.

Rodieck RW, Binmoeller KF, Dineen J (1985) Parasol and midget ganglion cells of the human retina. J Comp Neurol 233:115-132.

Schein SJ (1988) Anatomy of macaque fovea and spatial densities of neurons in foveal representation. J Comp Neurol 269:479-505.

Schein SJ, de Monasterio FM (1987) Mapping of retinal and geniculate neurons onto striate cortex of macaque. J Neurosci 7:996-1009.

Schiller P, Logothetis NK, Charles ER (1990) Functions of the colour- opponent and broad-band channels of the visual system. Nature 343: 68-70.

Shapley R, Perry VH (1986) Cat and monkey retinal ganglion cells and their visual functional roles. Trends Neurosci 9:229-235.

Silveira LCL, Perry VH (1991) The topography of magnocellular projecting ganglion cells (M-ganglion cells) in the primate retina. Neuroscience 40:217-237.

Snyder AW, Miller WH (1977) Photoreceptor diameter and spacing for highest resolving power. J Opt Soc Am 67:696-698.

Thibos LN, Cheney FE, Walsh DJ (1987) Retinal limits to the detection and resolution of gratings. J Opt Soc Am 4:1524-1529.

Tyler CW, Chan H, Lui L (1992) Different spatial tunings for ON and OFF pathway stimulation. Ophthalmol Physiol Opt 12:233-240.

Vaney DI (1985) The morphology and topographic distribution of AII amacrine cells in the cat retina. Proc R Soc Lond [Biol] 224:475-488.

Vaney DI (1986) Morphological identification of serotonin-accumulating neurons in the living retina. Science 233:444-446.

Wässle H, Boycott BB (1991) Functional architecture of the mammalian retina. Physiol Rev 71:447-480.

Wässle H, Riemann HJ (1978) The mosaic of nerve cells in the mammalian retina. Proc $\mathrm{R}$ Soc Lond [Biol] 200:441-461.

Wässle H, Peichl L, Boycott BB (1981a) Morphology and topography of on- and off-alpha cells in the cat retina. Proc $R$ Soc Lond [Biol] $212: 157-175$.

Wässle H, Boycott BB, Illing R-B (1981b) Morphology and mosaic of on- and off-beta cells in the cat retina and some functional considerations. Proc R Soc Lond [Biol] 212:177-195.

Wässle H, Peichl L, Boycott BB (1981c) Dendritic territories of cat retinal ganglion cells. Nature 292:344-345.

Wässle H, Boycott BB, Rohrenbeck J (1989a) Horizontal cells in the monkey retina: cone connections and dendritic network. Eur J Neurosci 1:421-435.

Wässle H, Grünert U, Röhrenbeck J, Boycott BB (1989b) Cortical magnification factor and the ganglion cell density of the primate retina. Nature 341:643-646.

Wässle H, Grunert U, Röhrenbeck J, Boycott BB (1990) Retinal ganglion cell density and cortical magnification factor in the primate Vision Res 30:1897-1911.

Watanabe M, Rodieck RW (1989) Parasol and midget ganglion cells of the primate retina. J Comp Neurol 289:434-454.

Wertheim T (1891) Peripheral visual acuity. Reprint (Dunsky IL, transl), Am J Optom Physiol Opt 57:915-924, 1980.

Wiesel TN, Hubel DH (1966) Spatial and chromatic interactions in the lateral geniculate body of the rhesus monkey. J Neurophysiol 29: $1115-1156$.

Williams DR, Coletta NJ (1987) Cone spacing and the visual resolution limit. J Opt Soc Am 4:1514-1523.

Zemon V, Gordon J, Welch J (1988) Asymmetries in ON and OFF visual pathways of humans revealed using contrast-evoked cortical potentials. Vis Neurosci 1:145-150. 